\title{
Article \\ Functional Characterization of Tomato Phytochrome A and B1B2 Mutants in Response to Heat Stress
}

\author{
Islam M. Y. Abdellatif ${ }^{1,2}{ }^{\oplus}$, Shaoze Yuan ${ }^{1}$, Renhu Na ${ }^{1}$, Shizue Yoshihara ${ }^{3}{ }^{\circ}$, Haruyasu Hamada ${ }^{4}$, \\ Takuya Suzaki ${ }^{1,5}$, Hiroshi Ezura ${ }^{1,5}$ (i) and Kenji Miura ${ }^{1,5, * \mathbb{C}}$ \\ 1 Graduate School of Life and Environmental Sciences, University of Tsukuba, Tsukuba 305-8572, Japan; \\ islam_abdellatif@mu.edu.eg (I.M.Y.A.); yuanshaoze1994@yahoo.co.jp (S.Y.); \\ na.renhu.gb@un.tsukuba.ac.jp (R.N.); suzaki.takuya.fn@u.tsukuba.ac.jp (T.S.); \\ ezura.hiroshi.fa@u.tsukuba.ac.jp (H.E.) \\ 2 Department of Horticulture, Faculty of Agriculture, Minia University, El-Minia 61517, Egypt \\ 3 Department of Biological Science, Osaka Prefecture University, Sakai 599-8531, Japan; \\ yoshihara@b.s.osakafu-u.ac.jp \\ 4 Pharma and Supplemental Nutrition Solutions Vehicle, Kaneka Corporation, Iwata 438-0802, Japan; \\ haruyasu.hamada@kaneka.co.jp \\ 5 Tsukuba-Plant Innovation Research Center, University of Tsukuba, Tsukuba 305-8572, Japan \\ * Correspondence: miura.kenji.ga@u.tsukuba.ac.jp
}

check for updates

Citation: Abdellatif, I.M.Y.; Yuan, S.; Na, R.; Yoshihara, S.; Hamada, H.; Suzaki, T.; Ezura, H.; Miura, K. Functional Characterization of Tomato Phytochrome A and B1B2 Mutants in Response to Heat Stress. Int. J. Mol. Sci. 2022, 23, 1681. https://doi.org/10.3390/ ijms23031681

Academic Editor: Andrei Smertenko

Received: 21 December 2021

Accepted: 29 January 2022

Published: 31 January 2022

Publisher's Note: MDPI stays neutral with regard to jurisdictional claims in published maps and institutional affiliations.

Copyright: () 2022 by the authors Licensee MDPI, Basel, Switzerland. This article is an open access article distributed under the terms and conditions of the Creative Commons Attribution (CC BY) license (https:// creativecommons.org/licenses/by/ $4.0 /)$.

\begin{abstract}
Heat stress (HS) is a prevalent negative factor affecting plant growth and development, as it is predominant worldwide and threatens agriculture on a large scale. PHYTOCHROMES (PHYs) are photoreceptors that control plant growth and development, and the stress signaling response partially interferes with their activity. PHYA, B1, and B2 are the most well-known PHY types in tomatoes. Our study aimed to identify the role of tomato 'Money Maker' phyA and phyB1B2 mutants in stable and fluctuating high temperatures at different growth stages. In the seed germination and vegetative growth stages, the phy mutants were HS tolerant, while during the flowering stage the phy mutants revealed two opposing roles depending on the HS exposure period. The response of the phy mutants to HS during the fruiting stage showed similarity to WT. The most obvious stage that demonstrated phy mutants' tolerance was the vegetative growth stage, in which a high degree of membrane stability and enhanced water preservation were achieved by the regulation of stomatal closure. In addition, both mutants upregulated the expression of heat-responsive genes related to heat tolerance. In addition to lower malondialdehyde accumulation, the phy $A$ mutant enhanced proline levels. These results clarified the response of tomato phyA and phyB1B2 mutants to HS.
\end{abstract}

Keywords: tomato; PHYTOCHROME A; PHYTOCHROME B1B2; phyA; phyB1B2; heat tolerance; HS

\section{Introduction}

Abiotic stress caused by environmental changes negatively affects plant growth and development [1]. Global warming has greatly impacted agriculture [2], and in many areas of the world, heat stress (HS) is one of the most crucial threats to plant growth and development, as it leads to a severe reduction in economic yield by causing morphoanatomical, physiological, and biochemical changes in plants [3]. From 2050 to 2100, HS will likely negatively affect tomato growth and productivity in the open field and decrease the optimal areas for cultivation [4]. An approach to mitigate the adverse effects of HS is to develop crop plants with improved plant stress tolerance using various genetic methods [3].

Tomato (Solanum lycopersicum L.) is an economically important crop worldwide that is sensitive to a series of abiotic stresses, particularly extreme temperatures [5]. The optimum temperature for tomato growth, fruit set, and yield ranges between 21 and $29.5{ }^{\circ} \mathrm{C}$ during the day and between 18.5 and $21^{\circ} \mathrm{C}$ during the night [6].

PHYTOCHROMES (PHYs), which absorb red and far-red light, are the most characterized photoreceptors in plants [7]. Plant growth and development (from seed germination 
to flowering) can be controlled by PHYs. PHYs regulate both biotic stress and stress induced by abiotic factors, such as high and low temperatures, salinity, drought, toxic metals, ultraviolet $B$ radiation, and herbivory [8], by changing a wide range of biochemical and molecular responses [7]. The number and types of PHYs vary among plant species. Tomato and Arabidopsis contain five PHYs in their genomes. Tomato plants have PHYA, PHYB1, PHYB2, PHYE, and PHYF [9], whereas Arabidopsis contains PHYA-PHYE [10]. In rice, plants have only three $P H Y$, $P H Y A-P H Y C$ [11]. Bioinformatics analysis of microarrays has clarified the performance of Arabidopsis PHYA and PHYB photoreceptors in plant HS responses [12] and revealed that PHYB also functions as a photoreceptor and temperature sensor in Arabidopsis plants [13].

Previous studies have shown that phy mutants are tolerant to several abiotic stresses. Arabidopsis phyB mutants exhibit tolerance to HS by lowering the percentage of electrolyte leakage (EL) [14]. High evapotranspiration levels caused rapid wilting in tomato phy $A$ mutants compared to wild-type (WT) plants $[15,16]$, which was also observed after exposure to sunny summer days [17]. In addition, rice phyB mutants exhibit improved cold tolerance compared to WT plants because of their lower EL index and malondialdehyde (MDA) concentration [18]. Furthermore, under salinity stress, tobacco phyA, phyB, and phy $A B$ mutants exhibited greater tolerance than WT plants by lowering their EL and MDA accumulations as well as enhancing the transcript levels of their defense-associated genes and the activities of some antioxidant enzymes [19].

Generally, plants can adapt to environmental conditions by developing a dynamic response at the morphological, physiological, and biochemical levels [20], in addition to enhancing specific changes in their gene expression levels and metabolism [21]. Under HS conditions, plants modulate their physiological function to respond or adapt to temperature changes [22]. Cell membrane injury is one of the first effects of plant stress. Maintaining electrolytes and stability of the cell membrane are important components for plant tolerance to stress conditions, such as high-temperature stress [23]. Proline is an essential organic osmolyte [24]. Its accumulation is a common physiological response to a wide range of biotic and abiotic stresses [25], such as extreme temperatures [24], and it is associated with stress tolerance [26]. Membrane lipid peroxidation is a severe damaging effect of reactive oxygen species (ROS), and measuring MDA can detect this condition, which is an important indicator of oxidative lipid injury caused by environmental stress. Several studies have investigated the MDA levels in plants under different stress conditions [27]. Stomata are microscopic pores in the leaf epidermis that regulate transpiration and carbon dioxide uptake by plant leaves. The guard cells of stomata can sense various stress triggers and respond quickly to initiate closure under unfavorable conditions [28].

For plant molecular mechanisms, HEAT SHOCK TRANSCRIPTION FACTORS (HSFs) and HEAT SHOCK PROTEINS (HSPs) are important factors in HS response and the acquisition of heat tolerance in plants $[29,30]$. The HSFs involved in heat sensing and signaling conserve their structure and functionality throughout the eukaryotic kingdom and are main triggers for the expression of HSP genes [29]. Studies have identified and characterized the HSF gene family in many crop species, including tomatoes [31]. Strong induction occurs in response to HS, with stable expression levels under nonstressed conditions [29]. The production and activation of HSFs and HSPs play a key role in plant response and acclimation to HS [32-34].

High temperature directly affects tomato fruit setting [35] because of its negative influence on pollen release and viability, which are major factors limiting fruit set [36]. In addition, high temperatures increase the production of aborted flowers, poor flower fertilization, and parthenocarpic fruit [37].

Many studies have illustrated the role of $P H Y B$ in abiotic stresses such as those relating to light, heat, cold, drought, and salinity, while only a few have described the role of PHYA under these conditions. An ideal tool for studying the participation of $P H Y S$ in biotic and abiotic stress responses is to increase the availability of phy mutants in different plant 
species [38]. Therefore, this study aimed to identify the response of tomato PHYs A and B to HS during different growth stages using the phyA mutant and the phyB1B2 double mutant.

\section{Results}

\subsection{The Phenotype of phy Mutants in Response to HS}

2.1.1. Conservation of the Seed Germination Rate in phyA and phyB1B2 under HS

HS can reduce the seed germination potential, resulting in poor germination and stand establishment [39]. We studied the response of the phy mutants to HS at the seed germination stage by measuring the seed germination rate of the WT and the mutants at 25 and $37^{\circ} \mathrm{C}$ after incubation for one week. At $25^{\circ} \mathrm{C}$, phy $A$ showed a lower germination rate than WT and phyB1B2, with similar results at $37^{\circ} \mathrm{C}$. However, phyA did not show any marked difference at $37^{\circ} \mathrm{C}$ compared to the results at $25^{\circ} \mathrm{C}$. In addition, $\mathrm{HS}$ did not affect the germination rate of phyB1B2 compared to that at $25^{\circ} \mathrm{C}$, showing nonsignificant variance between both conditions. In contrast, the WT revealed a significant reduction in seed germination rate under HS conditions compared to that at $25^{\circ} \mathrm{C}$ (Figure $1 \mathrm{~A}$ ). These results indicate that $\mathrm{HS}$ did not affect seed germination of $p h y A$ and $p h y B 1 B 2$ at $37^{\circ} \mathrm{C}$ for 7 days.

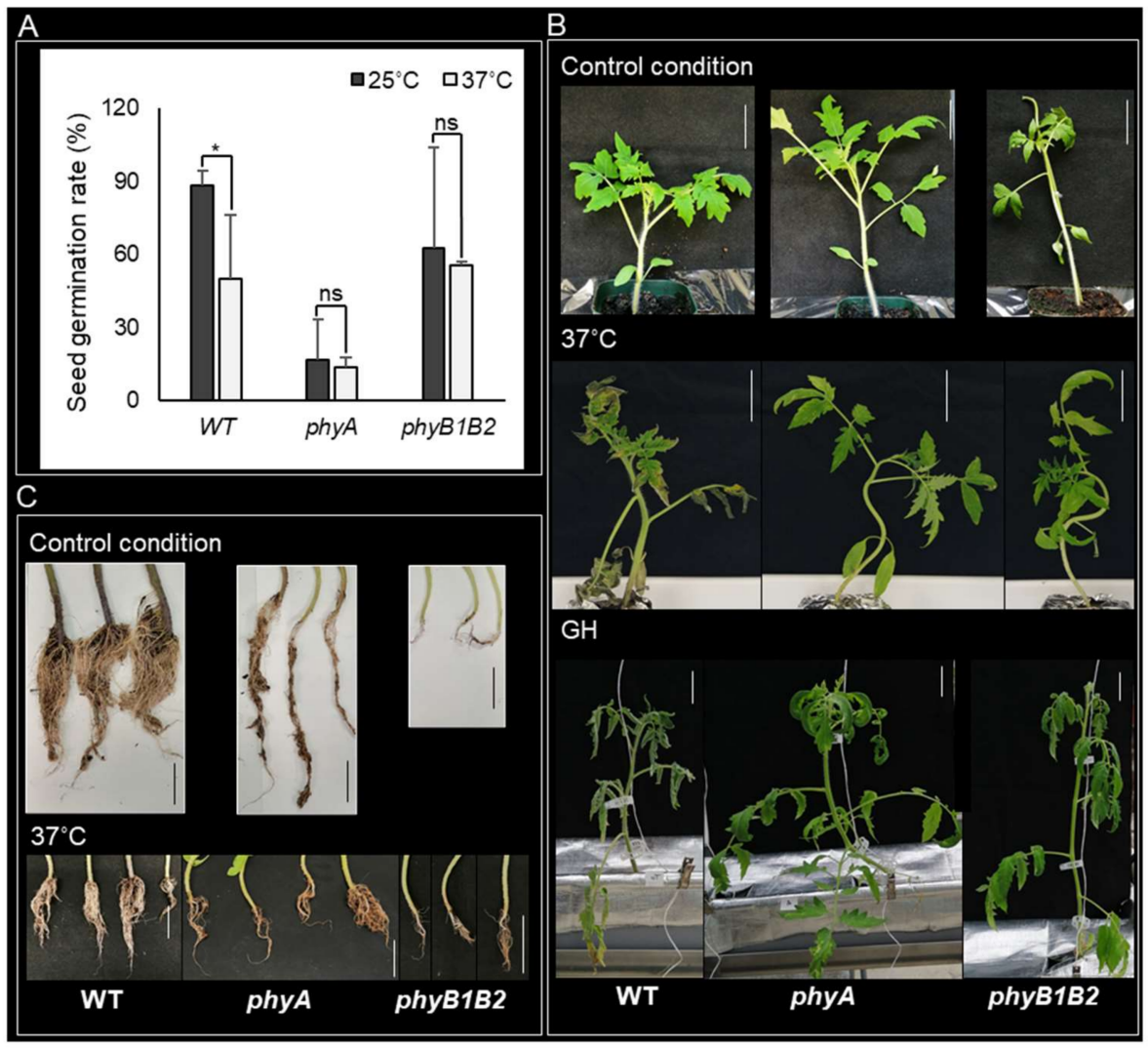

Figure 1. Plant features during seed germination and vegetative growth stages under heat stress (HS). (A) The seed germination rate of WT, phy A, and phyB1B2 after 7 days at 25 or $37^{\circ} \mathrm{C}$. (B) The phenotype of 4-week-old plants of tomato WT and phyA and phyB1B2 mutants under control conditions at $25^{\circ} \mathrm{C}$ and after exposure to $\mathrm{HS}$ at $37^{\circ} \mathrm{C}$ or fluctuating high temperature in greenhouse (GH) conditions for 2 weeks. (C) Root phenotype of 4-week-old plants of WT and phyA and phyB1B2 mutants after 2 weeks under control conditions at $25{ }^{\circ} \mathrm{C}$ or HS at $37^{\circ} \mathrm{C}$. The scale bars represent $5 \mathrm{~cm}$. Values represent the means $\pm S D$ ( $n \geq 10)$ from a representative of three biological replicates. The asterisk symbol $(*)$ represents statistically significant differences $(p<0.05)$, while ns represents statistically nonsignificant differences, between each genotype individually under 25 and $37{ }^{\circ} \mathrm{C}$ according to one-way ANOVA with post hoc Tukey HSD test. 


\subsubsection{Enhancement of Tomato Tolerance toward HS by phyA and phyB1B2 Mutation}

HS enhanced several morphological symptoms including scorching and sunburns of leaves and branches, as well as leaf senescence and abscission [40]. To investigate the response of tomato phy mutants to HS, we grew WT, phy A, and phyB1B2 under control $\left(25^{\circ} \mathrm{C}\right)$ and HS conditions $\left(37^{\circ} \mathrm{C}\right.$ and greenhouse $(\mathrm{GH})$ ). The $\mathrm{GH}$ minimum recorded temperature was approximately $20 \pm 3{ }^{\circ} \mathrm{C}$ while the maximum temperature was approximately $57 \pm 3{ }^{\circ} \mathrm{C}$ (Figure S1). The tomato cultivar 'Money Maker' was used as the WT. One-month-old plants exhibited healthy growth under control conditions. After exposing all genotypes to $37^{\circ} \mathrm{C}$, the WT leaves were severely damaged compared to those of phy $A$ and phyB1B2. Furthermore, under GH conditions, phy $A$ plants were tolerant to HS, whereas WT plants exhibited weak phenotypic growth with leaf senescence, and the phyB1B2 plants exhibited improved growth compared to the WT plants (Figure 1B). These results indicate that phy mutants promoted plant phenotypic tolerance to high-Tm stress.

In addition, we observed the root phenotype of WT and phy mutants grown at 25 and $37^{\circ} \mathrm{C}$. The WT root phenotype was more prolific than the phy mutant roots under both conditions (Figure 1C). This suggests that PHYA and B genes may be involved in root growth, since Arabidopsis phy $A B$ mutant seedlings showed a reduction in root elongation compared to WT [41].

\subsubsection{The phyA and phyB1B2 Flower and Fruit Phenotypic Response under HS}

Tomato flowers are highly susceptible to HS. High Tm can cause some morphological changes in the flower structure [42]. The flower phenotype was observed in flowered plants exposed to fluctuating high temperature in the $\mathrm{GH}$ for 14 and 35 days in comparison with flowers formed under $25^{\circ} \mathrm{C}$. The flowers of all genotypes did not show any marked difference under $25^{\circ} \mathrm{C}$. HS application for 14 days changed the flower phenotype of either WT or phyB1B2 compared to control conditions. At the same time, there was no difference in phyA flowers under either control or HS conditions. On the other hand, all genotypes showed different flower phenotype when exposed to HS for more than one month compared to plants under HS for two weeks. In $p h y A$, the sepaloid was the dominant part of the flowers showing long sepal. In addition, bloomed flowers did not appear under a long HS period (Figure 2A). These results show that HS affects flowers of WT and phy mutants after a long exposure time in a similar way.

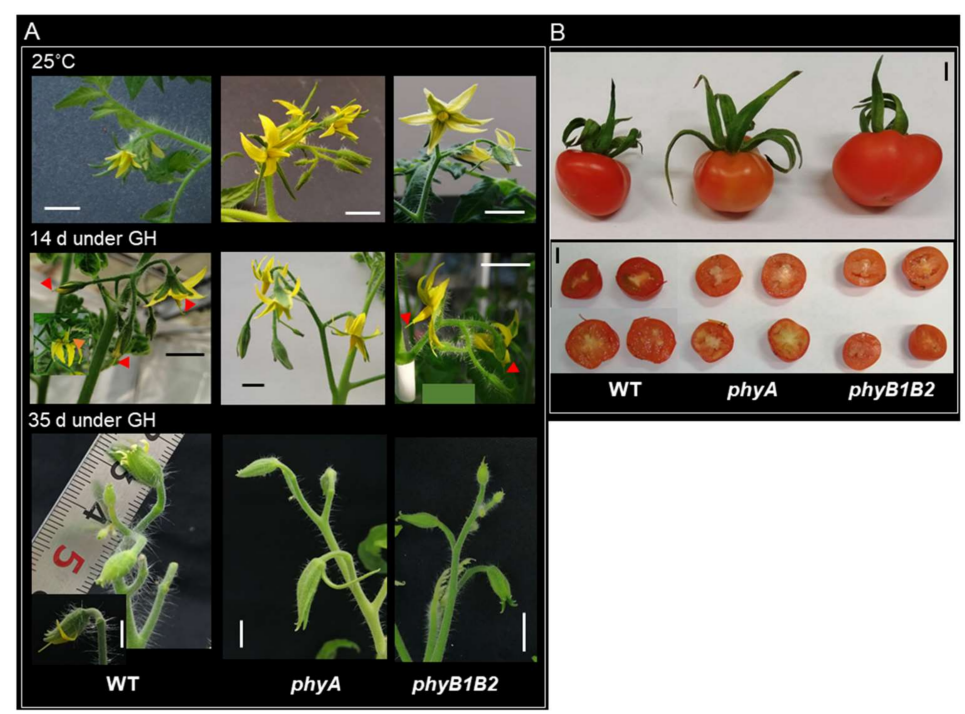

Figure 2. Flower and fruit phenotypic response under heat stress (HS). (A) The flower phenotype of WT, phy A, and phyB1B2 under $25^{\circ} \mathrm{C}$ and high-temperature stress under greenhouse (GH) conditions for 14 or 35 days. (B) Fruit phenotype and parthenocarpic phenomena of WT, phyA, and phyB1B2 under GH conditions. The scale bar represents $1 \mathrm{~cm}$. 
High Tm enhanced the parthenocarpic phenomena in tomato fruits [37]. Tm at $26{ }^{\circ} \mathrm{C}$ promoted small parthenocarpic tomato fruits, leading to low fruit yield [43]. The fruit phenotype and seed formation in the WT and phy mutants were investigated under GH conditions. The fruit phenotype of all genotypes did not show any difference. Furthermore, WT, phyA, and phyB1B2 produced parthenocarpic fruits under HS (Figure 2B). These results indicate that HS negatively affected WT, phyA, and phyB1B2 during the fruiting stage.

\subsubsection{Changes in Plant Vegetative Characteristics of phy Mutants in Response to HS}

High Tm adversely influences plant growth and development [44]. We measured the root surface area, length, stem height, stem thickness, plant fresh weight (FW), leaf number/plant, and average FW of leaves of one-month-old plants of WT and phy mutants after 2 weeks at 25 or $37^{\circ} \mathrm{C}$. The root surface area was highly significant in the WT compared to the phy mutants under both conditions. In addition, the phyB1B2 root surface area was significantly lower than that of phy $A$ under normal conditions, but not under HS conditions (Figure S2A).

The phyA mutant exhibited a long root length, which was not significantly different from that of WT, but differed significantly from phyB1B2 under control conditions (Figure S2B); however, the length significantly decreased after HS application compared to that at $25^{\circ} \mathrm{C}$. In contrast, there was no observable significant difference in the root length of WT or phyB1B2 at 25 and $37^{\circ} \mathrm{C}$ (Figure 3A).
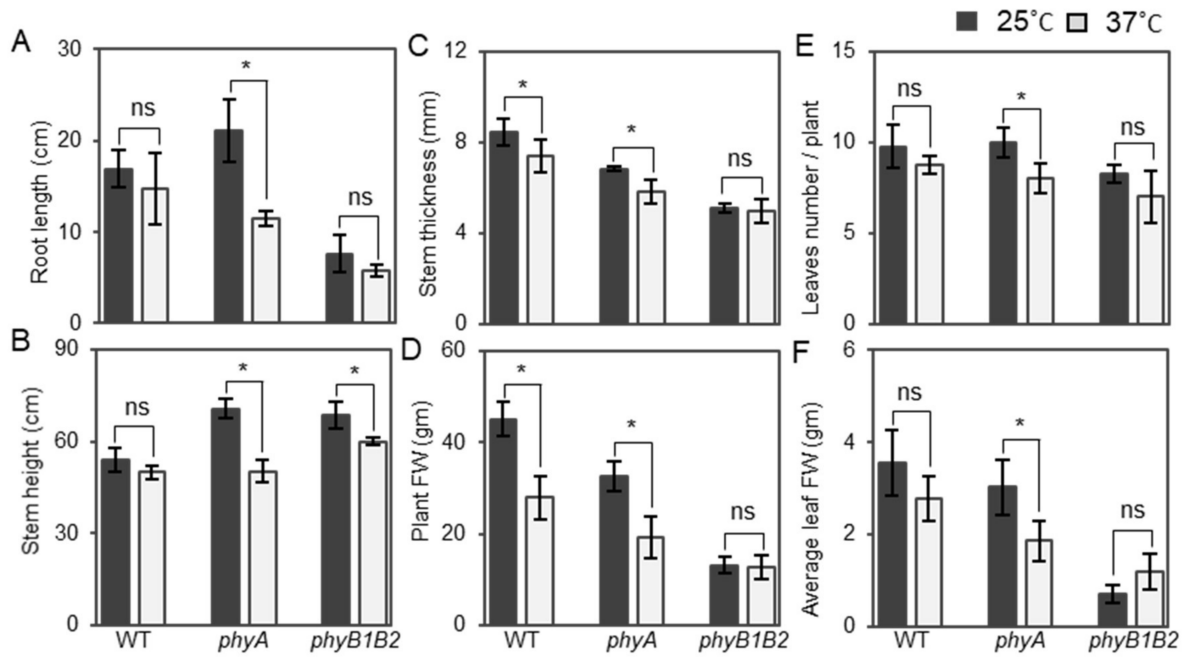

Figure 3. Root length and plant vegetative characteristics under heat stress (HS). Root length (A), plant stem height (B), stem thickness (C), plant FW (D), number of leaves/plant (E), and average leaf FW (F) of WT and phyA and phyB1B2 mutants after exposing 4-week-old plants to HS conditions at $37^{\circ} \mathrm{C}$ for 2 weeks in comparison with control conditions at $25^{\circ} \mathrm{C}$. Values represent the means $\pm \mathrm{SD}$ $(n=4)$ from a representative of three biologically independent experiments. The asterisk symbol ${ }^{*}$ ) represents statistically significant differences, while ns represents statistically nonsignificant differences, between each genotype individually under control and HS conditions according to Duncan's test $(p<0.05)$.

WT plants did not exhibit any marked differences in stem height, leaf number/plant, and average FW of leaves under both conditions, whereas there was a significant reduction in stem thickness and plant FW under HS conditions compared to the control. PhyA plants exhibited a significant reduction in all plant vegetative characteristics, such as stem height, stem thickness, plant FW, leaf number/plant, and average leaf FW at $37^{\circ} \mathrm{C}$ compared to $25^{\circ} \mathrm{C}$. In contrast, no difference was observed among all vegetative parameters, except for plant stem height in phyB1B2 (Figure 3B-F). Based on these results, the phyA mutant regulated the growth and enhanced the reduction of growth parameters at $37^{\circ} \mathrm{C}$ while the phyB1B2 mutant recorded lower values in most of the vegetative growth parameters. 


\subsubsection{Tomato phyA Mutant Inhibited Undesirable Flower Traits under HS}

High Tm causes undesirable defects in tomato flowers. There are indicated parameters related to floral characteristics that are used to evaluate tomato tolerance to HS in the flowering stage, such as stigma exertion, antheridia cone splitting, and flower number [45]. HS induced stigma exertion and antheridia cone splitting [46,47].

To determine the tolerance of phy mutants toward HS at the flowering stage, all genotypes endured fluctuating high temperatures in the GH for 14 days, where the minimum temperature reached $17.0^{\circ} \mathrm{C}$ and the maximum reached $50.5^{\circ} \mathrm{C}$ during flower formation (Figure S1). We recorded the total number of flowers/cluster, number of developed flowers/cluster, percentage of abnormal flowers/cluster, and percentage of stigma exertion/cluster. Under HS conditions, the WT achieved a higher number of flowers/cluster compared to $p h y A$, which was highly significant. At the same time, there was no marked variance between $\mathrm{WT}$ and phyB1B2. The number of developed flowers/cluster showed a significant increase in phyA compared to WT and phyB1B2. The difference in the percentage of abnormal flowers/cluster between WT and phyA was also highly significant $(p<0.01)$. PhyA showed a significantly lower percentage of abnormal flowers compared to WT, while they were not significantly different when compared to phyB1B2. PhyA revealed a significantly lower percentage of stigma-exerted flowers compared to WT plants, with no significant difference compared to phyB1B2. These results indicate that $p h y A$ is tolerant to high-temperature stress during the flowering phase for a few days of HS treatment, as opposed to WT and phyB1B2. Although phyB1B2 did not show a marked difference from phy $A$, it was still not significantly different from the WT plants (Figure 4A-D).
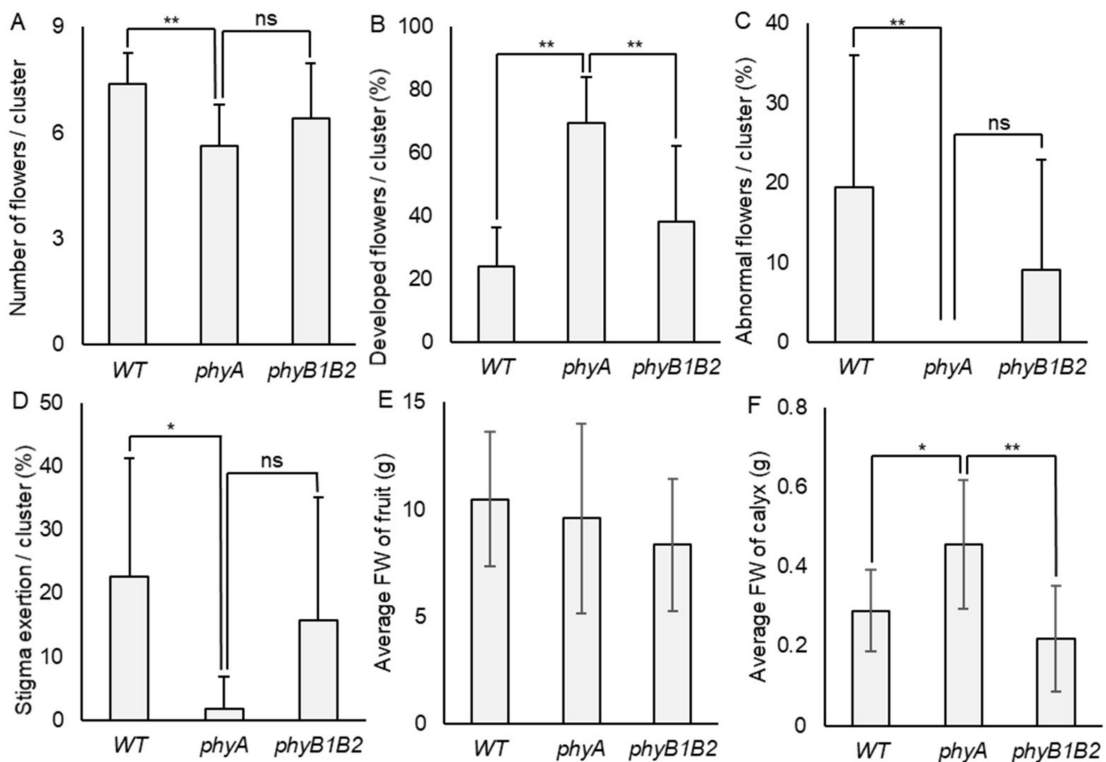

Figure 4. Flower and fruit characteristics under heat stress (HS). (A) The number of flowers/cluster, (B) the percentage of developed flowers/cluster, $(\mathbf{C})$ the percentage of abnormal flowers/cluster (that showed antheridia cone splitting), and (D) the percentage of stigma exertion/cluster were detected in WT, phyA, and phyB1B2 plants exposed to fluctuating high temperature for 14 days during flowering stage. (E) The average FW of fruit and (F) the average FW of calyx of WT, phyA, and phyB1B2 were recorded under greenhouse $(\mathrm{GH})$ conditions. The average temperature is recorded in Figure S1. The minimum Tm was $17.0^{\circ} \mathrm{C}$ while the maximum was $50.5^{\circ} \mathrm{C}$. Data represent the means $\pm \mathrm{SD}(\mathrm{n} \geq 8)$. The asterisk symbol $(*)$ represents statistically significant differences $(p<0.05)$, double asterisk symbol $\left.{ }^{* *}\right)$ expresses statistically highly significant differences $(p<0.01)$, and ns abbreviation represents statistically nonsignificant differences between all genotypes under HS conditions according to one-way ANOVA with post hoc Tukey HSD test. 


\subsubsection{Negative Effects of HS on Fruit Characteristics}

High Tm adversely affects fruit characteristics. Growth Tm at $29{ }^{\circ} \mathrm{C}$ significantly decreased tomato fruit weight and seed number/fruit compared to $25^{\circ} \mathrm{C}$ conditions [48]. We investigated the fruit characteristics of the WT and phy mutants under HS conditions, including the average FW of fruit and calyx. The average FW of fruit was affected by HS in all genotypes, with no significant difference among them (Figure 4E). The calyx FW in phyA was significantly increased $(p<0.05)$ compared to WT and was significantly $(p<0.01)$ higher than that of phyB1B2 (Figure 4F). These results indicate that HS negatively affected WT, phy $A$, and phyB1B2 during the fruiting stage.

\subsection{Tomato phyA and phyB1B2 Physiological Response under HS Conditions}

2.2.1. Inhibiting EL and MDA Accumulation and Enhancing Proline Accumulation under HS by Tomato phyA mutation

Membrane thermostability is a reliable parameter for screening plant tolerance to HS [49], and we determined the membrane stability of the phy mutants by measuring the EL of the tomato leaves. The EL of phyA grown at $37^{\circ} \mathrm{C}$ was the lowest among all genotypes, and the value for phyB1B2 was also significantly lower than that of WT (Figure 5A). HS reduced the EL of phy A and phyB1B2 by approximately $76 \%$ and $52 \%$, respectively, compared to that of the WT. These results suggest that phyA and phyB1B2 enhance membrane thermostability.

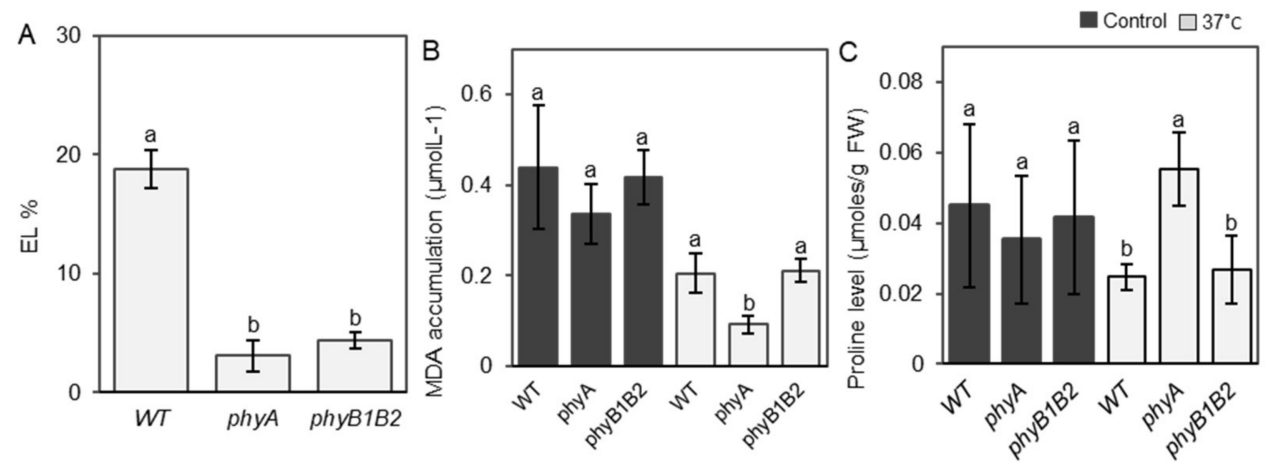

Figure 5. Electrolyte leakage (EL), MDA accumulation, and proline level under heat stress (HS). (A) The leaf EL of WT, phyA, and phyB1B2 after 2 weeks of $\mathrm{HS}$ at $37{ }^{\circ} \mathrm{C}$. Values represent the means $\pm \mathrm{SD}(\mathrm{n}=6)$ from a representative of three biologically independent experiments. MDA accumulation (B) and proline level (C) of WT and phyA and phyB1B2 mutants under 25 and $37^{\circ} \mathrm{C}$. Data represent the means $\pm S D(n \geq 4)$ from a representative of three biologically independent experiments. The letters written on the top of the error bars show the statistically significant differences between WT and phy mutants under HS conditions for EL parameter and under control and HS conditions individually for MDA and proline parameters, according to Duncan's test $(p<0.05)$. The same letter indicates no significant difference.

MDA is an end product produced as a result of polyunsaturated fatty acid peroxidation in cells and is a marker of oxidative stress [50]. MDA accumulation was not significantly different between WT and the phy mutants under control conditions, whereas phyA exhibited a significant reduction in MDA levels under HS compared to WT and phyB1B2 (Figure 5B).

Proline is an indicator of abiotic stress imposed on plants [51] and contributes to the stabilization of the subcellular structure and scavenging of free radicals [52]. At $25{ }^{\circ} \mathrm{C}$, proline levels of all genotypes were not significantly different, whereas at $37^{\circ} \mathrm{C}$, phy $\mathrm{A}$ achieved the highest proline value, which increased by approximately $42 \%$ and $52 \%$ in comparison with WT and phyB1B2, respectively (Figure 5C). These results suggest that the inhibition of membrane lipid peroxidation and accumulation of proline caused the heat tolerance phenotype of the phyA mutant. 


\subsubsection{Tomato phyA and phyB1B2 Can Change Stomata Features under HS Conditions}

Stomata are small pores in the above-ground organs of plants that facilitate the exchange of gases and water between plants and the surrounding environment. Their development is highly sensitive to environmental fluctuations, such as temperature stress [53]. We measured stomata number, stomatal pore length, and stomatal aperture of all genotypes grown at $25^{\circ} \mathrm{C}, 37^{\circ} \mathrm{C}$, and $\mathrm{GH}$ conditions. The stomata numbers of WT and the phy mutants did not show significant variance under control conditions, while at $37^{\circ} \mathrm{C}$ and $\mathrm{GH}$ conditions, WT plants contained a significantly higher number of stomata compared to the phy mutants (Figure 6A,D). There was no significant difference in stomatal pore length of WT and phy mutants under control and HS conditions (Figure 6B,E). The stomatal aperture was significantly smaller in the phy mutants than in the WT under control conditions. The phy $A$ mutant exhibited a significant reduction in stomatal aperture compared to WT plants grown at $37^{\circ} \mathrm{C}$ with no significant difference from phyB1B2 (Figure 6C). Under GH conditions, the stomatal apertures of the phy mutants were significantly smaller than those of the WT plants (Figure 6F). These results suggest that the phy mutants may decrease water loss when under HS by reducing the number of stomata and stomatal apertures.

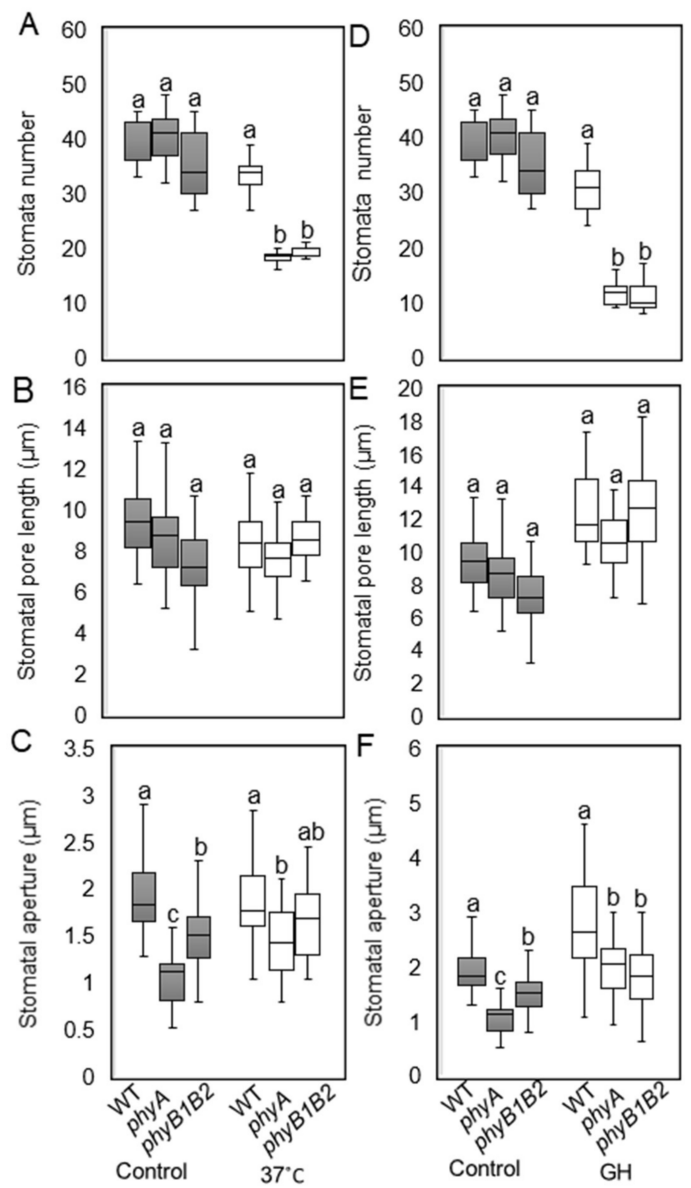

Figure 6. Microscopic analysis of stomata features under heat stress (HS). Stomata number $/ 92.7 \mathrm{~mm}^{2}$ (A,D), stomatal pore length $(\mu \mathrm{m})(\mathbf{B}, \mathbf{E})$, and stomatal aperture $(\mu \mathrm{m})(\mathbf{C}, \mathbf{F})$ after 2 weeks under $\mathrm{HS}$ at $37^{\circ} \mathrm{C}$ and greenhouse $(\mathrm{GH})$ conditions were investigated in comparison with control conditions at $25^{\circ} \mathrm{C}$. The boxplot values represent the recorded data $(n \geq 10)$ from a representative of three biologically independent experiments. The letters written on the top of the boxplots show the statistically significant differences between WT and phy mutants under control and HS conditions individually according to Duncan's test $(p<0.05)$. The same letter indicates no significant difference. 


\subsubsection{Enhancing Pollen Viability under HS in Tomato phyA and phyB1B2}

Pollen viability is a direct test for analyzing thermotolerance in plants during the flowering stage [35]. The pollen fertility test indicates the presence of viable or fertile pollen grains. The results of pollen fertility clarified that WT, phyA, and phyB1B2 differed in pollen tolerance to HS by showing different fertility percentages according to the period of HS application (Figure S3). In WT plants, the pollen fertility percentage significantly $(p<0.05)$ decreased after 18 days of exposure to fluctuating high temperatures under $\mathrm{GH}$ conditions. Similarly, the fertility of WT pollen after 22 and 28 days of HS had highly significant $(p<0.01)$ reductions compared to control conditions without any marked difference between pollen fertility of WT after 0 and 14 days of HS exposure. The pollen of phy $A$ did not show any marked difference in fertility at 0,14 , or 18 days of HS, while it revealed a highly significant decrease after 22 and 28 days of HS. The phyB1B2 mutant showed a nonsignificant variance in pollen fertility after application of HS for 14, 18, and 22 days compared to that at 0 days. However, there was a highly significant reduction in pollen fertility after 28 days of HS compared to that at 0 days (Figure 7). These results indicate that $p h y B 1 B 2$ pollen can survive under HS for a longer time, followed by phyA pollen when compared to WT under HS.

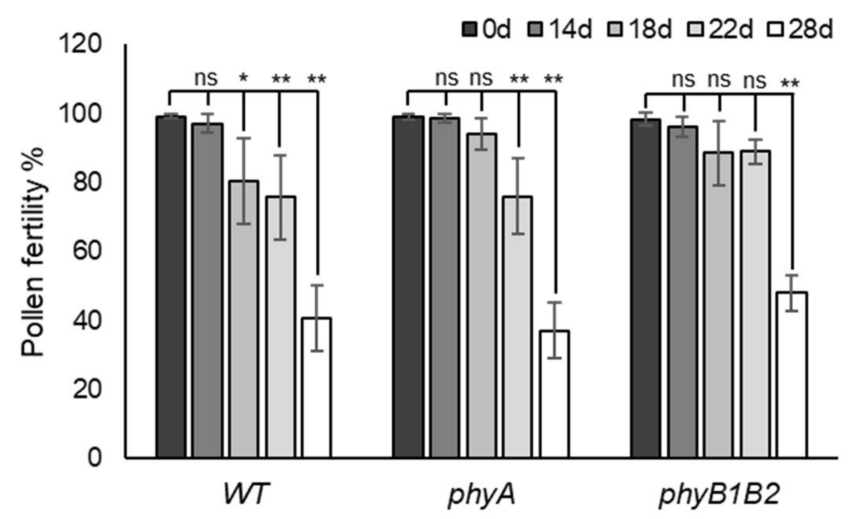

Figure 7. Pollen fertility under heat stress (HS). The pollen fertility percentage of WT, phyA, and phyB1B2 after $0,14,18,22$, and 28 days of HS under greenhouse $(\mathrm{GH})$ conditions. Data represent the means $\pm \mathrm{SD}(\mathrm{n}=4)$. The asterisk symbol $\left({ }^{*}\right)$ represents statistically significant differences $(p<0.05)$, double asterisk symbol $\left({ }^{* *}\right)$ expresses statistically highly significant differences $(p<0.01)$, and ns abbreviation represents statistically nonsignificant differences between each genotype individually after $0,14,18,22$, and 28 days of HS according to one-way ANOVA with post hoc Tukey HSD test.

\subsubsection{Inhibiting of Pollen Tube Growth by HS}

High Tm exceeding $30^{\circ} \mathrm{C}$ damages tomato pollen germination and pollen tube growth under in vitro and in vivo conditions [54]. We observed the pollen tube germination $24 \mathrm{~h}$ after in vivo hand pollination of the stigma at $25^{\circ} \mathrm{C}$. The results of in vivo pollen tube growth showed that WT and phy mutants germinated pollen after HS treatment of up to 28 days. However, few pollen tubes germinated under HS compared to those at 0 days (Figure S4). Based on these results, phy mutants showed the same response to high Tm stress on pollen tube growth as the WT.

\subsection{Tomato phyA and phyB1B2 Molecular Response under HS Conditions}

2.3.1. Tomato phy $A$ and $p h y B 1 B 2$ Enhanced the Expression of Some Heat- and Stress-Responsive Genes under HS during the Vegetative Growth Stage

HS reduces the efficiency of plant physiological and biochemical functions by modulating molecular mechanisms [55-57]. HSFs and HSPs play an important role in the capability to withstand several abiotic stresses such as HS [58,59]. We examined the expression levels of heat-responsive genes, including HSFs and HSPs in WT, phyA, and phyB1B2 at $37^{\circ} \mathrm{C}$. The expression levels of several HSF genes, such as HSFA2 and HSFB1, were upregulated 
in both the phyA and phyB1B2 mutants, and HSFA4a expression increased in phyB1B2, compared to the WT (Figure 8A). In addition, HSP90 gene was upregulated in phyB1B2 compared to the WT and phyA (Figure 8B). These results clarified the relationship between the phy mutants and heat-responsive genes under HS conditions.

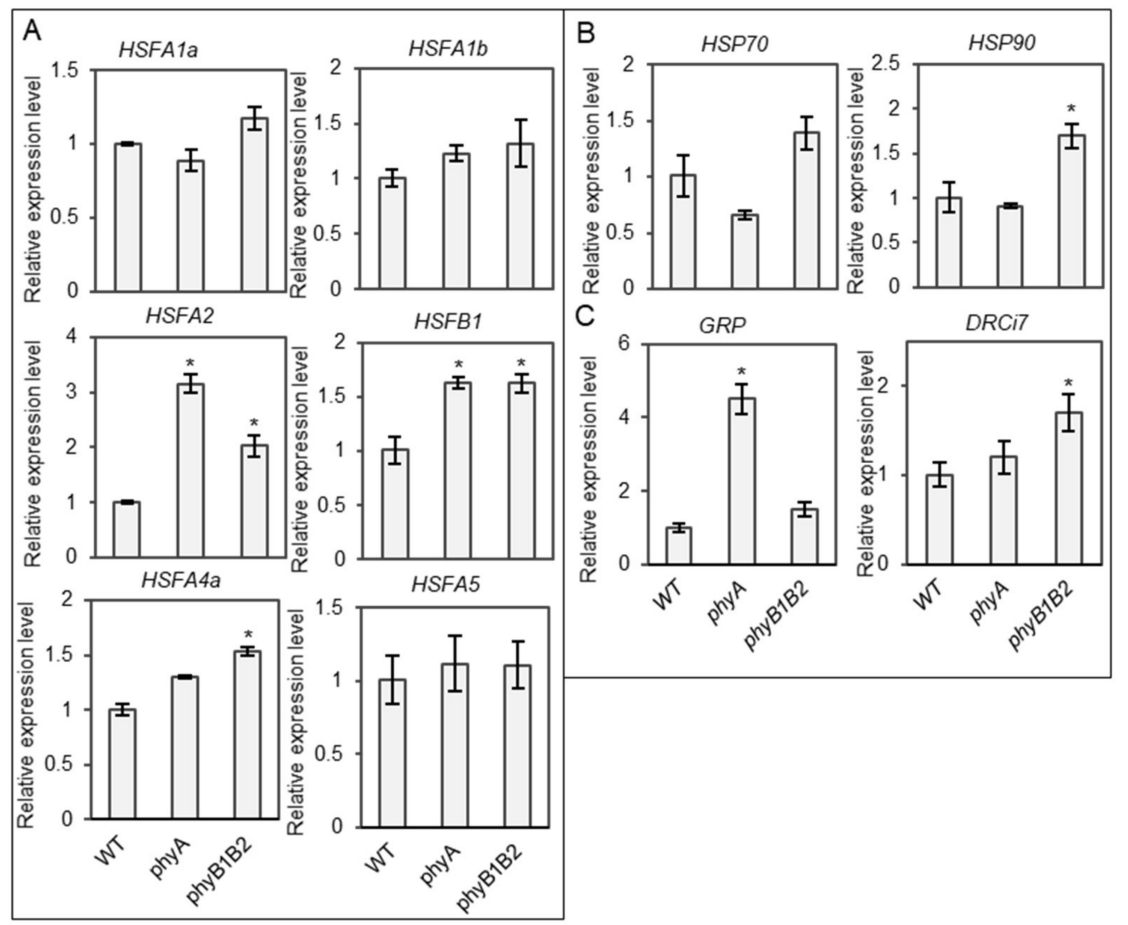

Figure 8. Relative gene expression levels under heat stress (HS) during vegetative growth stage. The expression levels of HSFs (HSFA1a, HSFA1b, HSFA2, HSFB1, HSFA4a, and HSFA5) (A), HSPs (HSP70 and HSP90) (B), and stress-responsive genes (GRP and DRCi7) (C) of one-month-old plants of WT and phyA and phyB1B2 mutants after 2 weeks under HS at $37^{\circ} \mathrm{C}$. The relative expression level of the WT was normalized to 1 . Error bars represent standard deviation $(n=3)$. The asterisk symbol ${ }^{*}$ ) represents statistically significant differences between WT and phy mutants using Duncan's test $(p<0.05)$.

We also investigated the expression levels of other stress-responsive genes, such as GLYCINE-RICH PROTEIN (GRP) and DEHYDRIN Ci7 (DRCi7). GRP plays a role in cellular stress responses and signaling. It has been indicated to be involved in the plant stress response in several plant species [60]. DEHYDRIN proteins are activated by various environmental factors [61]. GRP was highly expressed in $p h y A$, with a significant difference compared to WT and phyB1B2. DRCi7 expression level was higher in phyB1B2 than in WT and phyA (Figure $8 \mathrm{C}$ ). These results indicate that GRP may participate in phyA thermotolerant function.

PHYTOCHROME-INTERACTING FACTORS (PIFs) have roles in mediating heat responses in Arabidopsis [62]; therefore, we reviewed the expression levels of PIF4 and PIF7a. The expression level of these genes in phyA and phyB1B2 was similar to that in WT (Figure S5), which suggests that these genes did not participate in phy mutants' thermotolerance.

Furthermore, we examined the expression levels of SPEECHLESS (SPCH), 9-CISEPOXYCAROTENOID DIOXYGENASE 1 (NCED1), PROTEIN PHOSPHATASE 2C (PP2C), DELTA-1-PYRROLINE-5-CARBOXYLATE SYNTHASE (P5CS), and DELTA-1-PYRROLINE5-CARBOXYLATE REDUCTASE (P5CR) in WT and phyA and phyB1B2 mutants at $37^{\circ} \mathrm{C}$.

$\mathrm{SPCH}$ is one of the basic helix-loop-helix (bHLH) transcription factors that lead to stomatal development [63]. Arabidopsis $S P C H$ gene is necessary for asymmetric cell division regulation of stomatal lineage initiation [64]. The expression level of $S P C H$ was 
downregulated in both phy mutants compared to WT plants (Figure S6A). This result indicates the difference in stomata development between WT and phyA and phyB1B2 mutants.

The NCED enzyme controls the accumulation of ABA, which is an important plant stress-signaling hormone [65]. Furthermore, PP2Cs are involved in the ABA signaling pathway [66]. The expression level of NCED1 and PP2C was enhanced in phyB1B2 mutant compared to WT, but there was no significant difference between WT and phyA mutant (Figure S6B,C). According to these results, it appears that ABA plays a role in phyB1B2 under HS.

P5CS and P5CR are the key enzymes for the proline biosynthesis pathway in plants [67]. The phyA mutant represented a higher expression of P5CR and P5CS genes compared to WT and phyB1B2 mutant (Figure S6D,E). This result indicates that proline has a role in phyA mutant under HS.

2.3.2. Relative Expression of Some Heat- and Stress-Responsive Genes as Well as Flower Controller Genes during the Flowering Stage

After the initiation of flowering, we subjected plants to $\mathrm{HS}$ at $37^{\circ} \mathrm{C}$ for one month to check the expression levels of HSFs and HSPs, as well as the stress-responsive genes GRP and DRCi7. The WT and phy mutants did not show any significant variation in the expression levels of HSF and HSP genes. DRCi7 expression was significantly upregulated in phy mutants compared to that of WT. These results suggest that the heat- and stressresponsive genes did not play an obvious role during the flowering stage to promote heat tolerance in phy mutants (Figure 9A,B).

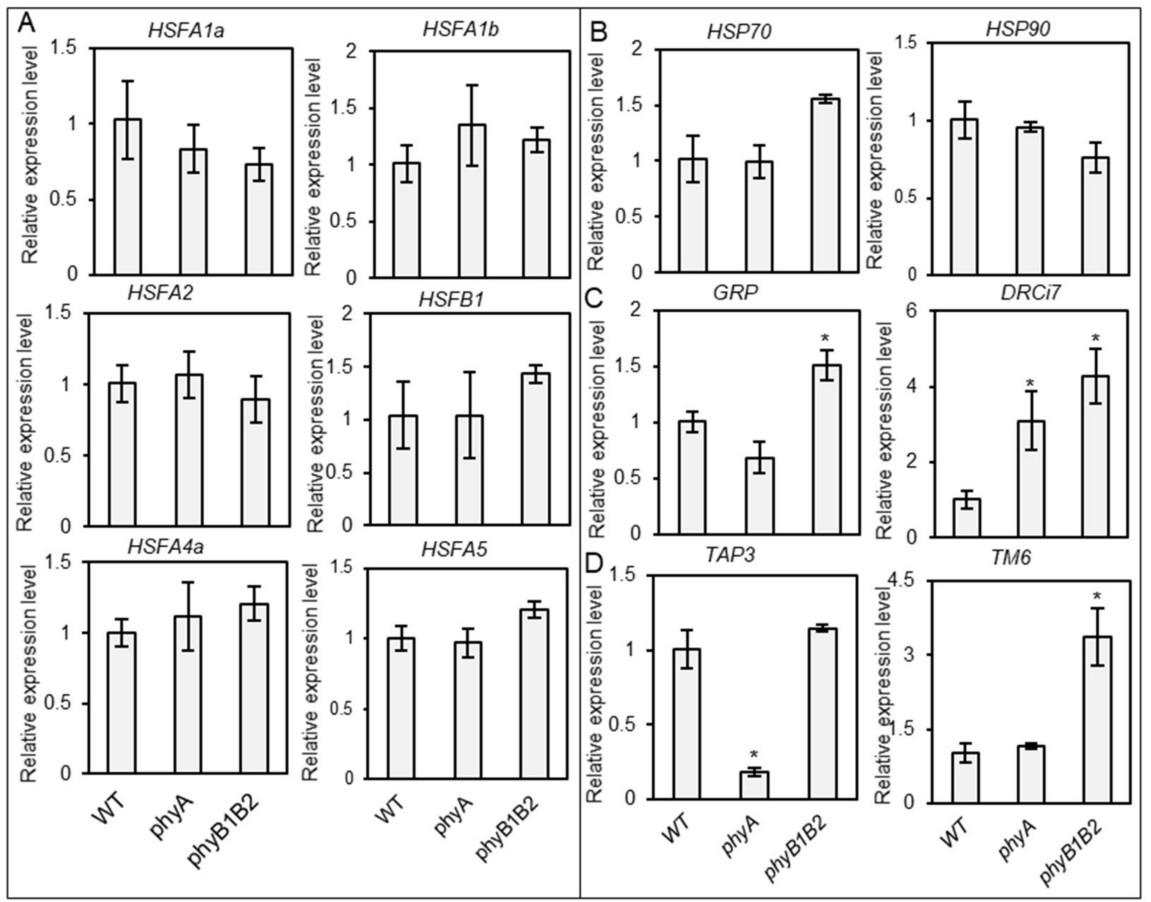

Figure 9. Relative gene expression level under heat stress (HS) during the flowering stage. The expression level of HSFs (HSFA1a, HSFA1b, HSFA2, HSFB1, HSFA4a, and HSFA5) (A), HSPs (HSP70 and HSP90) (B), and stress-responsive genes (GRP and DRCi7) (C) of WT and phyA and phyB1B2 mutants after one month under $\mathrm{HS}$ at $37^{\circ} \mathrm{C}$ during the flowering stage. Flower-related genes (TAP3 and TM6) (D) were observed after 35 days under greenhouse (GH) conditions when plants showed abnormal flower structures. The relative expression level of the WT was normalized to 1. Error bars represent standard deviation $(n \geq 3)$. The asterisk symbol $(*)$ represents statistically significant differences between WT and phy mutants using Duncan's test $(p<0.05)$. 
B-class MADS-box genes are involved in the specification of petal and stamen organ identity as well as in organ maturation control [68]. Tomato contains a single euAP3 lineage gene (Tomato APETALA3 (TAP3)) and a single tomato MADS-box gene 6 lineage (TM6), which play distinct roles in floral development. TAP3 is required to identify the petal and stamen, while TM6 is important for stamen differentiation [69]. We investigated the relative expression levels of TAP3 and TM6 in sampled flowers after 35 days under GH conditions. TAP3 was significantly downregulated in $p h y A$ compared to WT and phyB1B2, with no significant difference between them. TM6 was highly expressed in phyB1B2 compared to WT and phy A, without any marked difference between the last two varieties (Figure 9D). Based on these results, the floral development of $p h y A$ and phyB1B2 mutant flowers was controlled differently than that of WT.

\section{Discussion}

In our study, we screened the response of $p h y A$ and $p h y B 1 B 2$ tolerance to hightemperature stress compared to the 'Money Maker' WT under different growth stages from seed germination to fruiting stage, and we observed the response of these mutants to HS during seed germination, vegetative growth, flowering, and fruiting stages.

Our findings demonstrated that tomato phyA and phyB1B2 exhibited tolerance to HS during seed germination and the vegetative growth phase and for a short time of HS during the flowering stage. A long period of HS during the flowering or fruiting stage returned a response similar to that of the WT, which showed a sensitive response under all growth phases.

For the seed germination stage, both phy mutants showed nonsignificant differences in seed germination rate under normal and HS conditions, whereas the WT germination rate was negatively affected by HS, which indicates that both phy mutants can grow in hot seasons (Figure 1A).

During the vegetative growth stage, phy $A$ and $p h y B 1 B 2$ exhibited high tolerance to HS by enhancing the plant mechanism to cope with high-temperature stress. Inducing damage to plasma membranes in plants is an important side effect of HS [70]. Tomato phyA and phyB1B2 exhibited lower EL compared to WT under HS (Figure 5A), even though the tomato 'Money Maker' is classified as having moderate heat tolerance [71], indicating that tomato phy $A$ and phyB1B2 are highly tolerant mutants of HS that enhance membrane thermostability. Increased leaf temperature is a result of HS, which in turn inhibits the activity of enzymatic antioxidants and considerably increases the MDA level in the leaves [72,73]. Tomato phyA inhibited the production of MDA under HS (Figure 5B), which could be an indicator of the inhibition of polyunsaturated fatty acid peroxidation in the cells and the reduction in oxidative damage to membrane lipids, which then enhance heat tolerance. The accumulation of osmoprotectants is an adaptive mechanism in plants against environmental stresses such as heat tolerance [74] and increases plant survival by protecting the cellular structure [75]. Under high temperatures, plants accumulate different osmolytes, such as proline [76]. Tomato phyA enhanced proline accumulation under HS conditions via enhancing the expression of P5CS and P5CR genes that control proline biosynthesis, suggesting that proline accumulation is involved in the heat tolerance of phy $A$ (Figures 5C and S6D,E).

In addition, under the vegetative growth stage, both phy mutants exhibited a reduced number of stomata compared to the WT under HS (Figure 6A,D), and phyA exhibited a decrease in stomatal aperture (Figure 6C,F). In Arabidopsis, spch mutant did not produce stomata or lineages [64]. Tomato phyA and phyB1B2 mutants showed a downregulation in the expression level of SPCH gene compared to WT plants (Figure S6A), which may be one of the reasons for the stomata number reduction in phy mutants. It is plausible that water preservation also enhanced the heat tolerance of $p h y A$ and $p h y B 1 B 2$. Decreased stomatal closure and accelerated water loss speed enhanced HS sensitivity in transgenic OsMDHAR4-overexpressing rice [77]. Moreover, ABA is a key molecule that activates plant 
reactions to stress conditions, such as HS. It induces the accumulation of different proteins involved in stress acclimation and regulates stomatal closure under HS conditions [78].

Furthermore, the basic network among HSFA1a, HSFA2, and HSFB1 activity controls the HS response in tomatoes [79]. In addition, HSP accumulation protects the cell system from HS and enhances several functions and mechanisms to cope with HS [80]. In tomato phyB1B2, the upregulation of HSFA2, HSFB1, HSFA4a, and HSP90 expression levels may enhance thermotolerance (Figure $8 \mathrm{~A}, \mathrm{~B}$ ). The results showed that the expression levels of HSFA2 and HSFB1 were upregulated in phyA (Figure 8A). HSFA2 is an ideal transcriptional activator during the HS response [81]. Meanwhile, HSFA4a is involved in the regulation of abiotic stress tolerance, such as salt tolerance in Arabidopsis [82] and cadmium tolerance in wheat and rice [83]. GRP is involved in the defense system of plants under biotic and abiotic stresses and has a high glycine content [84]. Tomato phyA showed a high expression level of GRP under HS (Figure 8C), which might play a role in heat tolerance.

HS negatively affects pollen development and fertility, which reduces fruit setting [85]. Over a short period (less than 14 days) under fluctuating high temperature in the GH, phy $A$ exhibited a significantly enhanced percentage of developed flowers compared to WT and phyB1B2 (Figure 4B). However, phyB1B2 produced fertile pollen for a longer time under HS, followed by phyA, in comparison with WT pollen, which quickly reacted to high temperatures (Figure 7). Stigma exertion and antheridia cone splitting are floral characteristics used to evaluate HS tolerance [45]. PhyA achieved a significantly lower percentage of stigma-exerted and abnormal flowers compared to WT within 2 weeks under fluctuating high temperature; at the same time, no marked difference occurred when compared to phyB1B2 (Figure 4C, D). Although phyA showed heat tolerance by floral characteristics during the early exposure period to HS, its abnormal floral structure was enhanced by long HS application during the flowering phase (Figure 2A). In tomato, the homozygous mutation in TAP3 showed a classic B-class gene loss-of-function phenotype, which formed a complete transformation of the petals into sepaloid structures and the stamens into carpel-like organs [69]. This might explain the conversion in the flower structure of $p h y A$ due to the downregulation of TAP3 by showing a lower expression level compared to WT and phyB1B2 after exposure to HS for 35 days (Figure 9D). The long sepals were confirmed by the results of fruit calyx, which significantly increased in phyA compared to WT and phyB1B2 (Figure 4F). In addition, in phyA, the enhanced heat-responsive genes and GRP that were upregulated during the vegetative growth stage did not show a marked difference compared to WT under long periods of HS during the flowering stage. The phyB1B2 showed a nonsignificant variance in the expression level of all studied heat-responsive genes during the long exposure to HS during the flowering stage (Figure 9A,B). These results confirm that $p h y A$ and $p h y B 1 B 2$ did not enhance HS tolerance during the flowering stage when exposed to a long period of high-temperature stress, as did the WT.

In tomatoes, small parthenocarpic fruit is one of the side effects of high temperature, which leads to a decrease in yield [86]. All observed fruit in WT plants and phy mutants were parthenocarpic, and the average FW of the fruits was low, indicating that phy $A$ and phyB1B2 did not enhance HS tolerance during the fruiting stage as observed with WT.

Taken together, tomato phy mutants have a different response to high-temperature stress, as determined by the growth stage. The vegetative growth stage had the greatest growth, showing a high HS tolerance. Therefore, tomato phy $A$ is a thermotolerant mutant that enhances membrane stability, proline accumulation, and water preservation by reducing stomata number and stomatal aperture and upregulating the expression levels of HSFA2, HSFB1, and GRP. In addition, it inhibited MDA accumulation in the leaves (Figure 10A). Tomato phyB1B2 is a heat-tolerant mutant that enhances membrane stability and expression levels of HSFA2, HSFB1, HSFA4a, and HSP90. In addition, it inhibited water loss by decreasing the number of stomata (Figure 10B). 
A
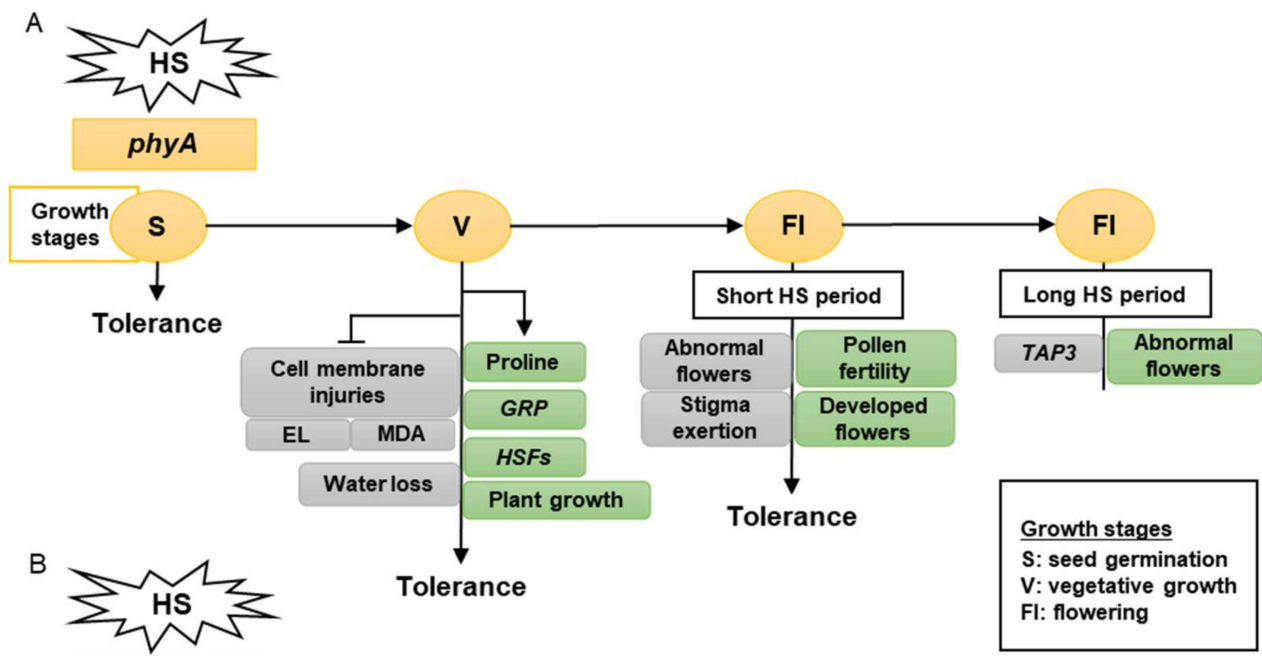

phyB1B2

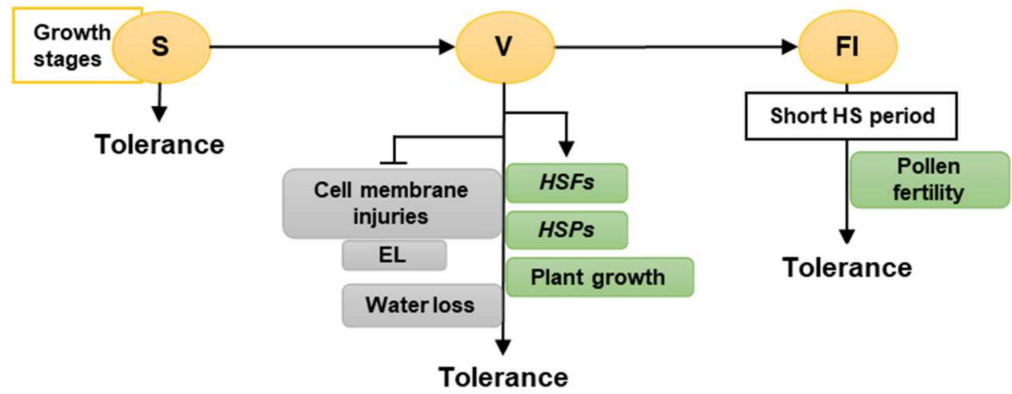

Figure 10. The model shows the response of $p h y A(\mathbf{A})$ and phyB1B2 (B) mutations at different growth stages under heat stress (HS). The gray rectangles show the factors inhibited while the green rectangles illustrate the factors enhanced by stress application. The growth stages that were shortened in $\mathrm{S}, \mathrm{V}$, and $\mathrm{Fl}$ were the seed germination, vegetative growth, and flowering stages, respectively. The phy mutants exhibited tolerance to HS during S, V, and Fl stages. In S stage, the seed germination rates of both phy mutants were not significantly affected by HS compared to control conditions (A, B). In V stage, phyA enhanced the proline production, HSFs, GRP, and plant growth (A), while phyB1B2 enhanced the upregulation of HSFs and HSPS as well as plant growth (B). In addition, both phy mutants inhibited cell membrane injuries (A, B). In Fl stage, phy mutants enhanced pollen fertility for a longer time compared to WT (A, B). Moreover, phyA exhibited an increase in the percentage of developed flowers and an inhibition in the percentage of abnormal and stigma-exerted flowers compared to WT. During a long HS application in the Fl stage, phyA exhibited enhanced abnormal flower formation via downregulation of TAP3 which enhanced sepal and petal conversion (A).

Finally, using plant genome editing on PHYA or B genes in other plant crops could be a good method of enhancing crop tolerance to HS. The genome editing method is a powerful technique for producing varieties; thus, several genome-edited plants are currently being produced $[87,88]$. Mutations in HSFA6 $a$ and HSFA6b, created by CRISPR/Cas9, are more tolerant to abiotic stresses such as ABA, mannitol, and sodium chloride [89]. Researchers have developed several mutants, such as the tomato ead1 mutant and soybean $h s p 90 A 2$ mutant, using CRISPR/Cas9. The tomato ead1 mutant exhibited short roots and increased sensitivity to ABA [90]. The soybean hsp90A2 mutant is sensitive to HS, has decreased chlorophyll content, and has high levels of lipid peroxidation [91]. Generally, genome editing techniques introduce mutations in the targeted genes. Mutations in negative regulators enhance tolerance to abiotic stress. Thus, PHYA and PHYB1B2 are good target genes for enhancing abiotic stress tolerance. 


\section{Materials and Methods}

\subsection{Plant Materials and Growth Conditions}

We used the tomato (Solanum lycopersicum L. 'Money Maker') WT, phyA mutant, and phyB1B2 double mutant [92] to study the role of tomato PHYs A, B1, and B2 in HS at the stages of seed germination, vegetative growth, flowering, and fruiting. We grew the seeds in soil or rockwool cubes and incubated them at $25^{\circ} \mathrm{C}$ for a long-day photoperiod (16 h light/8 h dark).

Plants endured HS under two different conditions: stable high temperature at $37^{\circ} \mathrm{C}$ or fluctuating high temperature under $\mathrm{GH}$ conditions. In the $\mathrm{GH}$, the minimum temperature recorded was approximately $20 \pm 3{ }^{\circ} \mathrm{C}$ during the night, while the maximum was approximately $57 \pm 3^{\circ} \mathrm{C}$ in the daytime during the summer seasons of 2019, 2020, and 2021 in Tsukuba City, Japan (Figure S1). We recorded GH temperature and humidity during the stress period using a Fujita Watch-Logger (KT-255F, Fujita Electric Works, Ltd., Kanagawa, Japan).

The plant ages differed when we applied HS according to the target growth stage to check the response of the phy mutants to HS conditions. To check the vegetative growth stage, we exposed one-month-old plants to HS, while for the flowering and fruiting stages, we transferred the plants to HS conditions after flowering.

\subsection{Phy Responses to HS during the Seed Germination Stage} Seed Germination Rate

We incubated the seeds in wet tissue at 25 and $37^{\circ} \mathrm{C}$ for one week and calculated the germination percentage using the following formula: seed germination rate $=$ (number of germinated seeds/total number of seeds) $\times 100$.

\subsection{Phy Responses to HS during the Vegetative Growth Stage}

\subsubsection{Morphological Phenotype}

We measured the morphological phenotypic characteristics, such as root surface area, root length, stem height (from the soil surface), stem thickness, plant FW, leaf number/plant, and leaf FW of tomato plants.

To analyze the root surface area, we viewed the image data using the ImageJ software version 1.51 (https:/ /imagej.nih.gov/ij/download.html).

\subsubsection{EL}

We analyzed the EL of tomato leaves as previously described [93]. Briefly, we washed the leaf surface with Milli-Q water (MQ) to remove any ions from the surface and then flooded the leaves in a tube filled with MQ to cover all the leaf parts. The tube stayed in a hot water bath at $43 \pm 1{ }^{\circ} \mathrm{C}$ for $1 \mathrm{~h}$. When the temperature decreased to $20-25^{\circ} \mathrm{C}$, we measured the ionic conductivity 1 (C1), followed by autoclaving the samples at $121{ }^{\circ} \mathrm{C}$ for $10 \mathrm{~min}$ and re-examining the ionic conductivity 2 (C2) when the samples cooled to $20-25{ }^{\circ} \mathrm{C}$. We used a conductivity meter (Lutron Electronics Co., Inc., Upper Saucon Township, PA, USA) for the ionic conductivity measurements and calculated the EL percentage using the following formula: $\mathrm{EL}(\%)=\mathrm{C} 1 / \mathrm{C} 2 \times 100$.

\subsubsection{Measuring Proline and MDA Levels}

Proline content of the leaf samples was determined as described [94], and a DU-800 spectrophotometer was used to measure the absorbance at $520 \mathrm{~nm}\left(\mathrm{~A}_{520}\right)$ (Beckman Coulter, Inc., Brea, CA, USA) for the calculation of the proline level using the following equation:

$$
\begin{aligned}
\text { Proline }(\mu \mathrm{mol} / \mathrm{g}) & \\
= & \frac{\text { A } 520(\mu \mathrm{g} \text { prolinemL }) \times \text { Toluene amount }(\mathrm{mL})}{115.13} \\
/ & \frac{\text { Sample } \mathrm{FW}(\mathrm{g})}{5}
\end{aligned}
$$


We measured the MDA level as described [95] and calculated it using the following formula: $\mathrm{MDA}(\mu \mathrm{mol} / \mathrm{L})=\left(6.45 \times\left(\mathrm{A}_{532}-\mathrm{A}_{600}\right)-0.56 \times \mathrm{A}_{450}\right)$.

\subsubsection{Microscopic Analysis for Stomata}

To prepare the leaf samples for checking stomata conditions, we collected fresh leaflets and pasted a thick tape on the upper surface, which we then gently pulled from the leaflet to tear off the epidermis to access the thin transparent layer of surface cells. After placing the epidermis layer on a microscope slide, we cut the leaf using a sharp scalpel, added one drop of water, and placed a coverslip on the sample. We used an Olympus BX50 microscope (Olympus, Tokyo, Japan) to determine the stomata number, pore length, and aperture, with the first item under $40 \times$ magnification (counting area $92.7 \mathrm{~mm}^{2}$ ) and the latter two under $100 \times$ magnification.

\subsubsection{RNA Isolation and Quantitative RT-PCR}

To check the heat- and stress-responsive genes during the vegetative growth stage, we extracted total RNA from the leaves of one-month-old plants of WT and phy mutants after exposure to $\mathrm{HS}$ at $37^{\circ} \mathrm{C}$ for two weeks, while for the flowering stage, we used leaf samples from flower-initiated plants after exposure to $\mathrm{HS}$ at $37^{\circ} \mathrm{C}$ for one month. For the expression levels of TAP3 and TM6, we used flower samples from flower-initiated plants after exposure to $\mathrm{HS}$ under GH conditions for 35 days.

We extracted the total RNA from WT and phy mutant plant samples using TRIzol reagent (Thermo Fisher Scientific, Waltham, MA, USA) according to the manufacturer's instructions and used $2 \mu \mathrm{g}$ to synthesize cDNA using a high-capacity cDNA reverse transcription kit (Thermo Fisher Scientific, Waltham, MA, USA). The primers used for the real-time PCR are listed in Table S1. RT-PCR amplification and detection were carried out using THUNDERBIRD SYBR qPCR Mix (Toyobo, Osaka, Japan) running on a 7900HT realtime PCR system (Applied Biosystems/Thermo Fisher Scientific, Waltham, MA, USA). The relative transcript abundance calculation utilized the comparative $C_{T}$ method as described previously [96] using $\Delta C_{T}$ of WT under HS as a subtrahend factor in the $\Delta \Delta C_{T}$ subtraction formula for comparison with the phy mutants as follows: $\Delta \Delta \mathrm{C}_{\mathrm{T}}\left(\Delta \mathrm{C}_{\mathrm{T}}-\Delta \mathrm{C}_{\mathrm{T}}\right.$, WT (stress) $)$. The tomato EXPRESSED gene was an endogenous control for gene expression analyses [97].

\subsection{Phy Responses to HS during Flowering and Fruiting Growth Stage}

\subsubsection{Pollen Fertility and Pollen Tube Growth Test}

To extract the pollen grains, we collected newly bloomed flowers (7-10 flowers) from plants every day under GH conditions, isolated the anther cones from the flowers, and left them to dry for 3-4 $\mathrm{h}$. We divided the anther cone into $2-3$ parts and remove the pollen grains by knocking on the cones. Eppendorf $1.5 \mathrm{~mL}$ tubes held the pollen for microscopic analysis of pollen fertility and pollen tube growth.

To analyze pollen fertility, we stained the pollen with iodine potassium iodide (IKI) as described previously [98] and observed it using an Olympus BX50 microscope. We manually counted at least four different microscopic sections of the fertile pollen for each period using the Microsoft Paint application (Microsoft windows, version 20H2 @ Microsoft Corporation)

The day after emasculating the mother flowers one day before opening, they were manually cross-pollinated using the extracted pollen after stress treatment. After $24 \mathrm{~h}$, we collected the pistils and immersed them in a fixing solution (consisting of 3:1 ETOH 100\%:acetic acid 100\%) for $12 \mathrm{~h}$, followed by immersion in ETOH $75 \%$ for $6-8 \mathrm{~h}$ and transfer to a softening solution consisting of $\mathrm{NaOH} 5 \mathrm{M}$ for $12-16 \mathrm{~h}$. We prepared the aniline blue working solution one day before use by diluting the aniline blue stock $0.01 \%(\mathrm{~V}: \mathrm{V})$ with $\mathrm{K}_{2} \mathrm{HPO}_{4}(0.1 \mathrm{M}, \mathrm{pH} 10) 10$ times and conserving it at $4{ }^{\circ} \mathrm{C}$ in the dark overnight. We then transferred the pistils into aniline blue working solution for $24 \mathrm{~h}$, placed them on a glass slide using glycerol $100 \%$ as a mounting agent, and strongly pressed the cover glass to flatten the sections. Observation of the sections utilized an Olympus BX50 UV microscope. 


\subsubsection{Flower Characteristics}

We determined the number of flowers/cluster, percentage of developed flowers/cluster, percentage of abnormal flowers/cluster, and percentage of stigma exertion/cluster for the flowers of WT and phy mutants under GH conditions.

\subsubsection{Fruiting Characteristics}

The average fruit FW, average calyx FW, and parthenocarpic phenomena were observed to determine the response of WT and phy mutants to HS under GH conditions.

\subsection{Statistical Analyses}

We used analysis of variance test (ANOVA) to analyze the quantitative data, with the means compared by Duncan's multiple range test $(p<0.05)$ or post hoc Tukey HSD test.

Supplementary Materials: Supplementary materials can be found at https:/ /www.mdpi.com/ article/10.3390/ijms23031681/s1.

Author Contributions: Conceptualization, T.S., H.H., H.E. and K.M.; methodology, I.M.Y.A., S.Y. (Shaoze Yuan), R.N., S.Y. (Shizue Yoshihara), T.S. and K.M.; validation, I.M.Y.A. and S.Y. (Shaoze Yuan); investigation, I.M.Y.A., S.Y. (Shaoze Yuan) and R.N.; formal analysis, I.M.Y.A. and K.M.; writing-original draft, I.M.Y.A. and K.M. All authors contributed to the article and approved the submitted version. The author responsible for distribution of materials integral to the findings presented in this article in accordance with the policy described in the Instructions for Authors (www.plantphysiol.org) is Kenji Miura (miura.kenji.ga@u.tsukuba.ac.jp). All authors have read and agreed to the published version of the manuscript.

Funding: This work has been supported by a JSPS Grant-in-Aid for Scientific Research (20K21302); a Cooperative Research Grant of the Plant Transgenic Design Initiative (PTraD) by the Gene Research Center, Tsukuba Plant Innovation Research Center (T-PIRC); and the Program on Open Innovation Platform with Enterprise, Research Institute and Academia, Japan Science and Technology Agency (JST-OPERA, JPMJOP1851).

Data Availability Statement: Data is contained within the article or supplementary materials.

Acknowledgments: The authors wish to thank Yuri Nemoto, Yumiko Iguchi, Yuriko Nagai, and Kazuko Ito at the University of Tsukuba for technical support. Islam M. Y. Abdellatif is funded by a full scholarship from the Ministry of Higher Education of the Arab Republic of Egypt to study his Ph.D.

Conflicts of Interest: H.H. is employed by Kaneka Corporation. H.E. and K.M. received research support from Kaneka Corporation. The remaining authors declare that the research was conducted in the absence of any commercial or financial relationships that could be construed as a potential conflict of interest.

\section{References}

1. Zhou, R.; Yu, X.; Ottosen, C.-O.; Rosenqvist, E.; Zhao, L.; Wang, Y.; Yu, W.; Zhao, T.; Wu, Z. Drought Stress Had a Predominant Effect over Heat Stress on Three Tomato Cultivars Subjected to Combined Stress. BMC Plant Biol. 2017, 17, 1-13. [CrossRef] [PubMed]

2. Wang, D.; Heckathorn, S.A.; Mainali, K.; Tripathee, R. Timing Effects of Heat-Stress on Plant Ecophysiological Characteristics and Growth. Front. Plant Sci. 2016, 7, 1629. [CrossRef]

3. Wahid, A.; Gelani, S.; Ashraf, M.; Foolad, M.R. Heat Tolerance in Plants: An Overview. Environ. Exp. Bot. 2007, 61, 199-223. [CrossRef]

4. Silva, R.S.; Kumar, L.; Shabani, F.; Picanço, M.C. Assessing the Impact of Global Warming on Worldwide Open Field Tomato Cultivation through CSIRO-Mk3.0 Global Climate Model. J. Agric. Sci. 2017, 155, 407-420. [CrossRef]

5. Zhou, R.; Yu, X.; Zhao, T.; Ottosen, C.-O.; Rosenqvist, E.; Wu, Z. Physiological Analysis and Transcriptome Sequencing Reveal the Effects of Combined Cold and Drought on Tomato Leaf. BMC Plant Biol. 2019, 19, 1-14. [CrossRef] [PubMed]

6. Jones, J.B., Jr. Tomato Plant Culture: In the Field, Greenhouse, and Home Garden, Second Edition, 2nd ed.; CRC Press: Boca Raton, FL, USA, 2007; ISBN 978-0-8493-7395-4.

7. Carvalho, R.F.; Campos, M.L.; Azevedo, R.A. The Role of Phytochromes in Stress Tolerance. In Salt Stress in Plants: Signalling, Omics and Adaptations; Ahmad, P., Azooz, M.M., Prasad, M.N.V., Eds.; Springer: New York, NY, USA, 2013; pp. 283-299, ISBN 9781461461081. 
8. Carvalho, R.F.; Campos, M.L.; Azevedo, R.A. The Role of Phytochrome in Stress Tolerance. J. Integr. Plant Biol. 2011, 53, 920-929. [CrossRef] [PubMed]

9. Alba, R.; Kelmenson, P.M.; Cordonnier-Pratt, M.M.; Pratt, L.H. The Phytochrome Gene Family in Tomato and the Rapid Differential Evolution of This Family in Angiosperms. Mol. Biol. Evol. 2000, 17, 362-373. [CrossRef]

10. Whitelam, G.C.; Devlin, P.F. Roles of Different Phytochromes in Arabidopsis Photomorphogenesis. Plant Cell Environ. 1997, 20, 752-758. [CrossRef]

11. Sun, W.; Hui Xu, X.; Lu, X.; Xie, L.; Bai, B.; Zheng, C.; Sun, H.; He, Y.; Xie, X. The Rice Phytochrome Genes, PHYA and PHYB, Have Synergistic Effects on Anther Development and Pollen Viability. Sci. Rep. 2017, 7, 6439. [CrossRef]

12. Song, J.; Liu, Q.; Hu, B.; Wu, W. Photoreceptor PhyB Involved in Arabidopsis Temperature Perception and Heat-Tolerance Formation. Int. J. Mol. Sci. 2017, 18, 1194. [CrossRef]

13. Legris, M.; Klose, C.; Burgie, E.S.; Rojas, C.C.R.; Neme, M.; Hiltbrunner, A.; Wigge, P.A.; Schäfer, E.; Vierstra, R.D.; Casal, J.J. Phytochrome B Integrates Light and Temperature Signals in Arabidopsis. Science 2016, 354, 897-900. [CrossRef] [PubMed]

14. Arico, D.; Legris, M.; Castro, L.; Garcia, C.F.; Laino, A.; Casal, J.J.; Mazzella, M.A. Neighbour Signals Perceived by Phytochrome B Increase Thermotolerance in Arabidopsis. Plant Cell Environ. 2019, 42, 2554-2566. [CrossRef] [PubMed]

15. Auge, G.A.; Rugnone, M.L.; Cortés, L.E.; González, C.V.; Zarlavsky, G.; Boccalandro, H.E.; Sánchez, R.A. Phytochrome A Increases Tolerance to High Evaporative Demand. Physiol. Plant 2012, 146, 228-235. [CrossRef]

16. Van Tuinen, A.; Kerckhoffs, L.H.J.; Nagatani, A.; Kendrick, R.E.; Koornneef, M. Far-Red Light-Insensitive, Phytochrome ADeficient Mutants of Tomato. Molec. Gen. Genet. 1995, 246, 133-141. [CrossRef] [PubMed]

17. D'Amico Damião, V.; Cruz, F.; Gavassi, M.; Santos, D.; Melo, H.C.; Carvalho, R. Photomorphogenic Modulation of Water Stress in Tomato (Solanum Lycopersicum L.): The Role of Phytochromes A, B1, and B2. J. Hortic. Sci. Biotechnol. 2015, 90, 25-30. [CrossRef]

18. He, Y.; Li, Y.; Cui, L.; Xie, L.; Zheng, C.; Zhou, G.; Zhou, J.; Xie, X. Phytochrome B Negatively Affects Cold Tolerance by Regulating OsDREB1 Gene Expression through Phytochrome Interacting Factor-Like Protein OsPIL16 in Rice. Front. Plant Sci. 2016, 7, 1963. [CrossRef] [PubMed]

19. Yang, T.; Lv, R.; Li, J.; Lin, H.; Xi, D. Phytochrome A and B Negatively Regulate Salt Stress Tolerance of Nicotiana Tobacum via ABA-Jasmonic Acid Synergistic Cross-Talk. Plant Cell Physiol. 2018, 59, 2381-2393. [CrossRef]

20. Lamaoui, M.; Jemo, M.; Datla, R.; Bekkaoui, F. Heat and Drought Stresses in Crops and Approaches for Their Mitigation. Front. Chem. 2018, 6, 26. [CrossRef]

21. Zhu, J.-K. Abiotic Stress Signaling and Responses in Plants. Cell 2016, 167, 313-324. [CrossRef]

22. Sakamoto, T.; Kimura, S. Plant Temperature Sensors. Sensors 2018, 18, 4365. [CrossRef]

23. Saelim, S.; Zwiazek, J.J. Preservation of Thermal Stability of Cell Membranes and Gas Exchange in High Temperature Acclimated Xylia Xylocarpa Seedlings. J. Plant Physiol. 2000, 156, 380-385. [CrossRef]

24. Ashraf, M.; Foolad, M.R. Roles of Glycine Betaine and Proline in Improving Plant Abiotic Stress Resistance. Environ. Exp. Bot. 2007, 59, 206-216. [CrossRef]

25. Verbruggen, N.; Hermans, C. Proline Accumulation in Plants: A Review. Amino Acids 2008, 35, 753-759. [CrossRef] [PubMed]

26. Fraire-Velázquez, S.; Balderas-Hernández, V.E. Abiotic Stress in Plants and Metabolic Responses. In Abiotic Stress—Plant Responses and Applications in Agriculture; Vahdati, K., Leslie, C., Eds.; IntechOpen: London, UK, 2013; pp. 25-48. Available online: https:/ / www.intechopen.com/chapters/43341 (accessed on 8 January 2021). [CrossRef]

27. Kong, W.; Liu, F.; Zhang, C.; Zhang, J.; Feng, H. Non-Destructive Determination of Malondialdehyde (MDA) Distribution in Oilseed Rape Leaves by Laboratory Scale NIR Hyperspectral Imaging. Sci. Rep. 2016, 6, 35393. [CrossRef] [PubMed]

28. Agurla, S.; Gahir, S.; Munemasa, S.; Murata, Y.; Raghavendra, A.S. Mechanism of Stomatal Closure in Plants Exposed to Drought and Cold Stress. Adv. Exp. Med. Biol. 2018, 1081, 215-232. [CrossRef] [PubMed]

29. Scharf, K.-D.; Berberich, T.; Ebersberger, I.; Nover, L. The Plant Heat Stress Transcription Factor (Hsf) Family: Structure, Function and Evolution. Biochim. Et Biophys. Acta (BBA)—Gene Regul. Mech. 2012, 1819, 104-119. [CrossRef] [PubMed]

30. Ohama, N.; Sato, H.; Shinozaki, K.; Yamaguchi-Shinozaki, K. Transcriptional Regulatory Network of Plant Heat Stress Response. Trends Plant Sci. 2017, 22, 53-65. [CrossRef] [PubMed]

31. Yang, X.; Zhu, W.; Zhang, H.; Liu, N.; Tian, S. Heat Shock Factors in Tomatoes: Genome-Wide Identification, Phylogenetic Analysis and Expression Profiling under Development and Heat Stress. PeerJ 2016, 4, e1961. [CrossRef] [PubMed]

32. Maestri, E.; Klueva, N.; Perrotta, C.; Gulli, M.; Nguyen, H.T.; Marmiroli, N. Molecular Genetics of Heat Tolerance and Heat Shock Proteins in Cereals. Plant Mol. Biol. 2002, 48, 667-681. [CrossRef] [PubMed]

33. Driedonks, N.; Rieu, I.; Vriezen, W.H. Breeding for Plant Heat Tolerance at Vegetative and Reproductive Stages. Plant Reprod. 2016, 29, 67-79. [CrossRef]

34. Comastri, A.; Janni, M.; Simmonds, J.; Uauy, C.; Pignone, D.; Nguyen, H.T.; Marmiroli, N. Heat in Wheat: Exploit Reverse Genetic Techniques to Discover New Alleles Within the Triticum Durum SHsp26 Family. Front. Plant Sci. 2018, 9, 1337. [CrossRef] [PubMed]

35. Paupière, M.J.; van Haperen, P.; Rieu, I.; Visser, R.G.F.; Tikunov, Y.M.; Bovy, A.G. Screening for Pollen Tolerance to High Temperatures in Tomato. Euphytica 2017, 213, 130. [CrossRef]

36. Sato, S.; Peet, M.M.; Thomas, J.F. Physiological Factors Limit Fruit Set of Tomato (Lycopersicon Esculentum Mill.) under Chronic, Mild Heat Stress. Plant Cell Environ. 2000, 23, 719-726. [CrossRef] 
37. Sato, S.; Peet, M.M.; Gardner, R.G. Formation of Parthenocarpic Fruit, Undeveloped Flowers and Aborted Flowers in Tomato under Moderately Elevated Temperatures. Sci. Hortic. 2001, 90, 243-254. [CrossRef]

38. Gavassi, M.A.; Monteiro, C.C.; Campos, M.L.; Melo, H.C.; Carvalho, R.F. Phytochromes Are Key Regulators of Abiotic Stress Responses in Tomato. Sci. Hortic. 2017, 222, 126-135. [CrossRef]

39. Fahad, S.; Bajwa, A.A.; Nazir, U.; Anjum, S.A.; Farooq, A.; Zohaib, A.; Sadia, S.; Nasim, W.; Adkins, S.; Saud, S.; et al. Crop Production under Drought and Heat Stress: Plant Responses and Management Options. Front. Plant Sci. 2017, 8, 1147. [CrossRef] [PubMed]

40. Hasanuzzaman, M.; Nahar, K.; Alam, M.; Roychowdhury, R.; Fujita, M. Physiological, Biochemical, and Molecular Mechanisms of Heat Stress Tolerance in Plants. Int. J. Mol. Sci. 2013, 14, 9643-9684. [CrossRef]

41. Correll, M.J.; Kiss, J.Z. The Roles of Phytochromes in Elongation and Gravitropism of Roots. Plant Cell Physiol. 2005, 46, 317-323. [CrossRef]

42. Alsamir, M.; Ahmad, N.M.; Keitel, C.; Mahmood, T.; Trethowan, R. Identification of High-Temperature Tolerant and Agronomically Viable Tomato (S. Lycopersicum) Genotypes from a Diverse Germplasm Collection. Adv. Crop Sci. Tech. 2017, 5, 10-4172. [CrossRef]

43. Adams, S.; Cockshull, K.; Cave, C. Effect of Temperature on the Growth and Development of Tomato Fruits. Ann. Bot. 2001, 88, 869-877. [CrossRef]

44. Bita, C.E.; Gerats, T. Plant Tolerance to High Temperature in a Changing Environment: Scientific Fundamentals and Production of Heat Stress-Tolerant Crops. Front. Plant Sci. 2013, 4, 273. [CrossRef] [PubMed]

45. Alsamir, M.; Mahmood, T.; Trethowan, R.; Ahmad, N. An Overview of Heat Stress in Tomato (Solanum Lycopersicum L.). Saudi J. Biol. Sci. 2021, 28, 1654-1663. [CrossRef] [PubMed]

46. Pan, C.; Yang, D.; Zhao, X.; Jiao, C.; Yan, Y.; Lamin-Samu, A.T.; Wang, Q.; Xu, X.; Fei, Z.; Lu, G. Tomato Stigma Exsertion Induced by High Temperature Is Associated with the Jasmonate Signalling Pathway. Plant Cell Environ. 2019, 42, 1205-1221. [CrossRef]

47. Müller, F.; Xu, J.; Kristensen, L.; Wolters-Arts, M.; de Groot, P.F.M.; Jansma, S.Y.; Mariani, C.; Park, S.; Rieu, I. High-TemperatureInduced Defects in Tomato (Solanum Lycopersicum) Anther and Pollen Development Are Associated with Reduced Expression of B-Class Floral Patterning Genes. PLoS ONE 2016, 11, e0167614. [CrossRef] [PubMed]

48. Peet, M.M.; Sato, S.; Gardner, R.G. Comparing Heat Stress Effects on Male-Fertile and Male-Sterile Tomatoes. Plant Cell Environ. 1998, 21, 225-231. [CrossRef]

49. Srinivasan, A.; Takeda, H.; Senboku, T. Heat Tolerance in Food Legumes as Evaluated by Cell Membrane Thermostability and Chlorophyll Fluorescence Techniques. Euphytica 1996, 88, 35-45. [CrossRef]

50. Gaweł, S.; Wardas, M.; Niedworok, E.; Wardas, P. Malondialdehyde (MDA) as a lipid peroxidation marker. Wiad. Lek. 2004, 57, 453-455.

51. Claussen, W. Proline as a Measure of Stress in Tomato Plants. Plant Sci. 2005, 168, 241-248. [CrossRef]

52. Kaur, G.; Asthir, B. Proline: A Key Player in Plant Abiotic Stress Tolerance. Biol. Plant. 2015, 59, 609-619. [CrossRef]

53. Samakovli, D.; Tichá, T.; Šamaj, J. HSP90 Chaperones Regulate Stomatal Differentiation under Normal and Heat Stress Conditions. Plant Signal. Behav. 2020, 15, 1789817. [CrossRef]

54. Karapanos, I.C.; Akoumianakis, K.A.; Olympios, C.M.; Passam, H.C. The Effect of Substrate, ADP and Uncoupler on the Respiration of Tomato Pollen during Incubation In Vitro at Moderately High Temperature. Sex. Plant Reprod. 2009, 22, 133-140. [CrossRef] [PubMed]

55. Djanaguiraman, M.; Perumal, R.; Jagadish, S.V.K.; Ciampitti, I.A.; Welti, R.; Prasad, P.V.V. Sensitivity of Sorghum Pollen and Pistil to High Temperature Stress. Plant Cell Environ. 2018, 41, 1065-1082. [CrossRef] [PubMed]

56. Muhlemann, J.K.; Younts, T.L.B.; Muday, G.K. Flavonols Control Pollen Tube Growth and Integrity by Regulating ROS Homeostasis during High-Temperature Stress. Proc. Natl. Acad. Sci. USA 2018, 115, E11188-E11197. [CrossRef] [PubMed]

57. Takahashi, F.; Shinozaki, K. Long-Distance Signaling in Plant Stress Response. Curr. Opin. Plant Biol. 2019, 47, 106-111. [CrossRef] [PubMed]

58. Guo, M.; Liu, J.-H.; Ma, X.; Luo, D.-X.; Gong, Z.-H.; Lu, M.-H. The Plant Heat Stress Transcription Factors (HSFs): Structure, Regulation, and Function in Response to Abiotic Stresses. Front Plant Sci. 2016, 7, 114. [CrossRef] [PubMed]

59. Ul Haq, S.; Khan, A.; Ali, M.; Khattak, A.M.; Gai, W.-X.; Zhang, H.-X.; Wei, A.-M.; Gong, Z.-H. Heat Shock Proteins: Dynamic Biomolecules to Counter Plant Biotic and Abiotic Stresses. Int. J. Mol. Sci. 2019, 20, 5321. [CrossRef]

60. Czolpinska, M.; Rurek, M. Plant Glycine-Rich Proteins in Stress Response: An Emerging, Still Prospective Story. Front. Plant Sci. 2018, 9, 302. [CrossRef]

61. Kosová, K.; Vítámvás, P.; Prášil, I.T. The Role of Dehydrins in Plant Response to Cold. Biol. Plant 2007, 51, 601-617. [CrossRef]

62. Fiorucci, A.-S.; Galvão, V.C.; Ince, Y.Ç.; Boccaccini, A.; Goyal, A.; Allenbach Petrolati, L.; Trevisan, M.; Fankhauser, C. PHYTOCHROME INTERACTING FACTOR 7 Is Important for Early Responses to Elevated Temperature in Arabidopsis Seedlings. New Phytol. 2020, 226, 50-58. [CrossRef]

63. Chen, L.; Wu, Z.; Hou, S. SPEECHLESS Speaks Loudly in Stomatal Development. Front. Plant Sci. 2020, 11, 114. [CrossRef]

64. De Marcos, A.; Houbaert, A.; Triviño, M.; Delgado, D.; Martín-Trillo, M.; Russinova, E.; Fenoll, C.; Mena, M. A Mutation in the BHLH Domain of the SPCH Transcription Factor Uncovers a BR-Dependent Mechanism for Stomatal Development1. Plant Physiol. 2017, 174, 823-842. [CrossRef] 
65. Liu, S.; Li, M.; Su, L.; Ge, K.; Li, L.; Li, X.; Liu, X.; Li, L. Negative Feedback Regulation of ABA Biosynthesis in Peanut (Arachis Hypogaea): A Transcription Factor Complex Inhibits AhNCED1 Expression during Water Stress. Sci. Rep. 2016, 6, 37943. [CrossRef] [PubMed]

66. Park, S.-Y.; Fung, P.; Nishimura, N.; Jensen, D.R.; Fujii, H.; Zhao, Y.; Lumba, S.; Santiago, J.; Rodrigues, A.; Chow, T.-F.F.; et al. Abscisic Acid Inhibits Type 2C Protein Phosphatases via the PYR/PYL Family of START Proteins. Science 2009, 324, $1068-1071$. [CrossRef]

67. Li, C.; Shuqiang, W.; Lei, H.; Yongqiang, Q.; Huali, Z.; Haibo, X.; Zhenyuan, S. Gene Cloning and Expression of the Pyrroline-5Carboxylate Reductase Gene of Perennial Ryegrass (Lolium Perenne). Hortic. Plant J. 2015, 1, 113-120. [CrossRef]

68. Li, Q.; Huo, Q.; Wang, J.; Zhao, J.; Sun, K.; He, C. Expression of B-Class MADS-Box Genes in Response to Variations in Photoperiod Is Associated with Chasmogamous and Cleistogamous Flower Development in Viola Philippica. BMC Plant Biol. 2016, 16, 151. [CrossRef] [PubMed]

69. De Martino, G.; Pan, I.; Emmanuel, E.; Levy, A.; Irish, V.F. Functional Analyses of Two Tomato APETALA3 Genes Demonstrate Diversification in Their Roles in Regulating Floral Development. Plant Cell 2006, 18, 1833-1845. [CrossRef]

70. Dhanda, S.S.; Munjal, R. Cell Membrane Stability: Combining Ability and Gene Effects under Heat Stress Conditions. Cereal Res. Commun. 2009, 37, 409-417. [CrossRef]

71. Alsadon, A.; Wahb-Allah, M.; Khalil, S. In Vitro Evaluation of Heat Stress Tolerance in Some Tomato Cultivars. J. King Saud Univ. 2006, 19, 13-24.

72. Hurkman, W.J.; Vensel, W.H.; Tanaka, C.K.; Whitehand, L.; Altenbach, S.B. Effect of High Temperature on Albumin and Globulin Accumulation in the Endosperm Proteome of the Developing Wheat Grain. J. Cereal Sci. 2009, 49, 12-23. [CrossRef]

73. Mohammed, A.R.; Tarpley, L. Effects of High Night Temperature and Spikelet Position on Yield-Related Parameters of Rice (Oryza Sativa L.) Plants. Eur. J. Agron. 2010, 33, 117-123. [CrossRef]

74. Asthir, B. Mechanisms of Heat Tolerance in Crop Plants. J. Plant Interact. 2015, 10, 1-21. [CrossRef]

75. Hare, P.D.; Cress, W.A.; Staden, J.V. Dissecting the Roles of Osmolyte Accumulation during Stress. Plant Cell Environ. 1998, 21, 535-553. [CrossRef]

76. Sairam, R.K.; Tyagi, A. Physiology and Molecular Biology of Salinity Stress Tolerance in Plants. Curr. Sci. 2004, 86, 407-421.

77. Liu, J.; Sun, X.; Xu, F.; Zhang, Y.; Zhang, Q.; Miao, R.; Zhang, J.; Liang, J.; Xu, W. Suppression of OsMDHAR4 Enhances Heat Tolerance by Mediating H2O2-Induced Stomatal Closure in Rice Plants. Rice 2018, 11, 1-12. [CrossRef]

78. Balfagón, D.; Zandalinas, S.I.; Gómez-Cadenas, A. High Temperatures Change the Perspective: Integrating Hormonal Responses in Citrus Plants under Co-Occurring Abiotic Stress Conditions. Physiol. Plant 2018, 165, 183-197. [CrossRef]

79. Hahn, A.; Bublak, D.; Schleiff, E.; Scharf, K.-D. Crosstalk between Hsp90 and Hsp70 Chaperones and Heat Stress Transcription Factors in Tomato. Plant Cell 2011, 23, 741-755. [CrossRef]

80. Hassan, M.U.; Chattha, M.U.; Khan, I.; Chattha, M.B.; Barbanti, L.; Aamer, M.; Iqbal, M.M.; Nawaz, M.; Mahmood, A.; Ali, A.; et al. Heat Stress in Cultivated Plants: Nature, Impact, Mechanisms, and Mitigation Strategies-A Review. Plant Biosyst.—Int. J. Deal. All Asp. Plant Biol. 2020, 155, 211-234. [CrossRef]

81. Baniwal, S.K.; Bharti, K.; Chan, K.Y.; Fauth, M.; Ganguli, A.; Kotak, S.; Mishra, S.K.; Nover, L.; Port, M.; Scharf, K.-D.; et al. Heat Stress Response in Plants: A Complex Game with Chaperones and More than Twenty Heat Stress Transcription Factors. J. Biosci. 2004, 29, 471-487. [CrossRef]

82. Pérez-Salamó, I.; Papdi, C.; Rigó, G.; Zsigmond, L.; Vilela, B.; Lumbreras, V.; Nagy, I.; Horváth, B.; Domoki, M.; Darula, Z.; et al. The Heat Shock Factor A4A Confers Salt Tolerance and Is Regulated by Oxidative Stress and the Mitogen-Activated Protein Kinases MPK3 and MPK61. Plant Physiol. 2014, 165, 319-334. [CrossRef]

83. Shim, D.; Hwang, J.-U.; Lee, J.; Lee, S.; Choi, Y.; An, G.; Martinoia, E.; Lee, Y. Orthologs of the Class A4 Heat Shock Transcription Factor HsfA4a Confer Cadmium Tolerance in Wheat and Rice. Plant Cell 2009, 21, 4031-4043. [CrossRef]

84. Ortega-Amaro, M.A.; Rodríguez-Hernández, A.A.; Rodríguez-Kessler, M.; Hernández-Lucero, E.; Rosales-Mendoza, S.; IbáñezSalazar, A.; Delgado-Sánchez, P.; Jiménez-Bremont, J.F. Overexpression of AtGRDP2, a Novel Glycine-Rich Domain Protein, Accelerates Plant Growth and Improves Stress Tolerance. Front. Plant Sci. 2015, 5, 782. [CrossRef]

85. Pham, D.; Hoshikawa, K.; Fujita, S.; Fukumoto, S.; Hirai, T.; Shinozaki, Y.; Ezura, H. A Tomato Heat-Tolerant Mutant Shows Improved Pollen Fertility and Fruit-Setting under Long-Term Ambient High Temperature. Environ. Exp. Bot. 2020, $178,104150$. [CrossRef]

86. Driedonks, N.J.W. From Flower to Fruit in the Heat-Reproductive Thermotolerance in Tomato and Its Wild Relatives. Ph.D.Thesis. Radboud University, Nijmegen, The Netherlands, 2018; p. 193.

87. Yamamoto, T.; Kashojiya, S.; Kamimura, S.; Kameyama, T.; Ariizumi, T.; Ezura, H.; Miura, K. Application and Development of Genome Editing Technologies to the Solanaceae Plants. Plant Physiol. Biochem. 2018, 131, 37-46. [CrossRef] [PubMed]

88. Bhat, M.A.; Bhat, M.A.; Kumar, V.; Wani, I.A.; Bashir, H.; Shah, A.A.; Rahman, S.; Jan, A.T. The Era of Editing Plant Genomes Using CRISPR/Cas: A Critical Appraisal. J. Biotechnol. 2020, 324, 34-60. [CrossRef]

89. Wenjing, W.; Chen, Q.; Singh, P.K.; Huang, Y.; Pei, D. CRISPR/Cas9 Edited HSFA6a and HSFA6b of Arabidopsis Thaliana Offers ABA and Osmotic Stress Insensitivity by Modulation of ROS Homeostasis. Plant Signal. Behav. 2020, 15, 1816321. [CrossRef] [PubMed] 
90. Wang, W.; Wang, X.; Wang, Y.; Zhou, G.; Wang, C.; Hussain, S.; Adnan; Lin, R.; Wang, T.; Wang, S. SlEAD1, an EAR MotifContaining ABA down-Regulated Novel Transcription Repressor Regulates ABA Response in Tomato. GM Crops Food 2020, 11, 275-289. [CrossRef]

91. Huang, Y.; Xuan, H.; Yang, C.; Guo, N.; Wang, H.; Zhao, J.; Xing, H. GmHsp90A2 Is Involved in Soybean Heat Stress as a Positive Regulator. Plant Sci. 2019, 285, 26-33. [CrossRef]

92. Weller, J.L.; Schreuder, M.E.L.; Smith, H.; Koornneef, M.; Kendrick, R.E. Physiological Interactions of Phytochromes A, B1 and B2 in the Control of Development in Tomato. Plant J. 2000, 24, 345-356. [CrossRef]

93. Miura, K.; Shiba, H.; Ohta, M.; Kang, S.W.; Sato, A.; Yuasa, T.; Iwaya-Inoue, M.; Kamada, H.; Ezura, H. SlICE1 Encoding a MYC-Type Transcription Factor Controls Cold Tolerance in Tomato, Solanum Lycopersicum. Plant Biotechnol. 2012, 29, 253-260. [CrossRef]

94. Khan, S.H.; Khan, A.; Litaf, U.; Shah, A.S.; Khan, M.A.; Bilal, M.; Usman Ali, M. Effect of Drought Stress on Tomato Cv. Bombino. Food Process Technol. 2015, 6, 2. [CrossRef]

95. Shi, X.; Jiang, F.; Wen, J.; Wu, Z. Overexpression of Solanum Habrochaites MicroRNA319d (Sha-MiR319d) Confers Chilling and Heat Stress Tolerance in Tomato (S. Lycopersicum). BMC Plant Biol. 2019, 19, 214. [CrossRef] [PubMed]

96. Miura, K.; Jin, J.B.; Lee, J.; Yoo, C.Y.; Stirm, V.; Miura, T.; Ashworth, E.N.; Bressan, R.A.; Yun, D.-J.; Hasegawa, P.M. SIZ1-Mediated Sumoylation of ICE1 Controls CBF3/DREB1A Expression and Freezing Tolerance in Arabidopsis. Plant Cell 2007, 19, 1403-1414. [CrossRef] [PubMed]

97. Choi, S.; Hoshikawa, K.; Fujita, S.; Thi, D.P.; Mizoguchi, T.; Ezura, H.; Ito, E. Evaluation of Internal Control Genes for Quantitative Realtime PCR Analyses for Studying Fruit Development of Dwarf Tomato Cultivar 'Micro-Tom'. Plant Biotechnol. 2018, 35, 225-235. [CrossRef] [PubMed]

98. Sulusoglu, M.; Cavusoglu, A. In Vitro Pollen Viability and Pollen Germination in Cherry Laurel (Prunus Laurocerasus L.). Sci. World J. 2014, 2014, 657123. [CrossRef] [PubMed] 